\title{
Asymmetric and Endogenous Within-Group Communication in Competitive Coordination Games
}

\author{
Timothy N. Cason a,* \\ Roman M. Sheremeta ${ }^{b, c}$ \\ Jingjing Zhang ${ }^{\mathrm{d}}$ \\ a Department of Economics, Krannert School of Management, Purdue University, \\ 403 W. State St., West Lafayette, IN 47906, U.S.A. \\ ${ }^{\mathrm{b}}$ Department of Economics, Weatherhead School of Management, Case Western Reserve \\ University, 11119 Bellflower Road, Cleveland, OH 44106, U.S.A. \\ ${ }^{c}$ Economic Science Institute, Chapman University, \\ One University Drive, Orange, CA 92866 \\ ${ }^{\mathrm{d}}$ Economics Discipline Group, University of Technology Sydney, \\ PO Box 123, Broadway NSW 2007 Sydney, Australia
}

February 20, 2017

\begin{abstract}
Within-group communication in competitive coordination games has been shown to increase competition between groups and lower efficiency. This study further explores potentially harmful effects of communication, by addressing the questions of (i) asymmetric communication and (ii) the endogenous emergence of communication. Our theoretical analysis provides testable hypotheses regarding the effect of communication on competitive behavior and efficiency. We test these predictions using a laboratory experiment. The experiment shows that although asymmetric communication is not as harmful as symmetric communication, it leads to more aggressive competition and lower efficiency relative to the case when neither group can communicate. Moreover, groups vote to endogenously establish communication channels even though they would earn higher payoffs if jointly they chose to restrict within-group communication.
\end{abstract}

JEL Classifications: C70, D72, H41

Keywords: between-group competition, within-group competition, communication, coordination, contests, experiments

\footnotetext{
* Corresponding author: Tim Cason; E-mail: cason@purdue.edu

We thank Jordi Brandts, Subhasish Chowdhury, David Cooper, Martin Dufwenberg, Enrique Fatas, Anya Samek, Marta Serra-Garcia, two anonymous referees, seminar participants at University of New South Wales, University of Technology, Sydney, Chapman University, Purdue University and participants at the Thurgau Experimental Economics Conference, the International Economic Science Association Meetings, the North-American Economic Science Association Meetings, the European Economic Science Association Meetings, and the workshop in honor of John Van Huyck for helpful discussions and comments. We retain responsibility for any errors. This research has been supported by National Science Foundation (SES-0721019).
} 


\section{Introduction}

Cheap talk can facilitate coordination on the efficient equilibrium in experimental games with Pareto-ranked equilibria (Cooper et al., 1992; Charness, 2000; Charness and Grosskopf, 2004; Duffy and Feltovich, 2002, 2006; Brandts and Cooper, 2007). For example, Van Huyck et al. (1993) demonstrate that pre-play communication is efficiency-enhancing in coordination games. Blume and Ortmann (2007) find that costless nonbinding messages, even when they have minimal information content, can facilitate quick convergence to the Pareto-efficient equilibrium. Since many economic interactions can be modeled as coordination games, this finding may have a very important general implication: improving communication in coordination games can increase efficiency and social welfare. However, this broad conclusion can be misleading. Indeed, Cason et al. (2012) show that allowing within-group communication in competitive coordination games, such as rent-seeking contests, may lead to more aggressive competition between groups. Therefore, the introduction of within-group communication in such environments may actually cause inefficiency and decrease social welfare.

This study further explores potentially harmful effects of within-group communication in competitive coordination games, by addressing two questions. The first question concerns with the effects of asymmetric communication: If only one of the two competing groups can communicate, does such asymmetric communication harm efficiency by increasing competition between groups? The second question concerns with the endogenous emergence of communication: Given that communication may potentially harm efficiency, do groups still choose to establish the "harmful" communication channel? To answer these questions, we reanalyze some existing data from and add two new treatments to the Cason et al. (2012) experiment that employs a weakest-link contest between two groups. 
The weakest-link contest combines features of a cooperative weakest-link game (Van Huyck et al., 1990) and a competitive rent-seeking contest (Tullock, 1980). One key characteristic of this type of contest is that coordination on higher efforts increases the probability of winning the prize, thus receiving potentially higher payoffs. Efforts are aggregated within each group with a weakest-link production technology, so the effective group effort equals the lowest effort expended by an individual in the group. The weakest-link feature of this contest resembles many real life competitions where the performance of the entire group depends on the worst performer within a group (Hirshleifer, 1983). For example, in many teamwork competitions each member of the team is responsible for a specific task. If any of the members performs his/her task poorly then the team loses the competition. Certain R\&D competitions have such characteristics. Also, in terrorist attacks and in some military battles, the attacker's objective is often to successfully attack one target, rather than a subset of targets (Clark and Konrad, 2007; Deck and Sheremeta, 2012).

In a group contest coordination on higher efforts increases the probability of winning the prize but decreases the competitor's payoff. Therefore, higher efforts may lead to lower efficiency due to the negative externality imposed on the competing group. This unique feature of the group contest has been used by researchers to examine questions about punishment and retaliation (Abbink et al., 2010), rent-seeking (Ahn et al., 2011), group structure (Sheremeta, 2011), and leadership (Eisenkopf, 2014). ${ }^{1}$ Previous studies have shown that when there is no within-group communication, group members are able to achieve a substantial level of coordination within each group (Sutter and Strassmair, 2009). Allowing within-group

\footnotetext{
${ }^{1}$ For a comprehensive review of these studies see Sheremeta (2017). Most contest studies find that subjects behave more aggressively than predicted and their behavior is heterogeneous (Sheremeta, 2013).
} 
communication leads to even better coordination, but as a result of more aggressive competition it also leads to lower efficiency (Cason et al., 2012; Brookins et al., 2015). ${ }^{2}$

Our experiment employs a weakest-link contest to further explore the potentially harmful effects of within-group communication in competitive coordination games. The weakest-link feature gives contestants the ability to lower unilaterally their own group's effort, thereby decreasing excessive effort expenditures and improving efficiency. Regarding the first question of asymmetric communication, we find that when only one group can communicate, the communicating group coordinates better and expends higher efforts than the non-communicating group. As a result, the communicating group earns payoffs similar to the baseline contest without any communication while the non-communicating group earns lower payoff. Allowing withingroup communication in both groups leads to even more aggressive competition and the lowest average payoffs in both groups. We use content analysis to analyze why communication is harmful and find that subjects often send messages expressing their desire to compete and win (significantly more so than messages about cooperation). Moreover, such messages are positively and significantly correlated with effort expenditures in the contest, which could partially explain overly aggressive competition in the presence of communication.

Regarding the second question of endogenous communication, we find that groups routinely choose to establish communication channels. As in the exogenous case, endogenously selected communication enhances coordination, but it also leads to more aggressive competition and lower efficiency. Choosing to communicate or not resembles a Prisoner's Dilemma game. By jointly choosing to restrict within-group communication both groups can earn higher payoffs, but incentives are such that choosing to communicate is a weakly dominant strategy. Even

\footnotetext{
${ }^{2}$ Although Sutter and Strassmair (2009) also document that communication within groups increases individual efforts, such efforts lead to higher payoffs and higher efficiency under their design.
} 
though communication is only a weakly dominant strategy, almost all groups choose to communicate. Such strong adoption of communication is unlikely due to only strategic reasons. Therefore, we provide several other explanations for this result, such as natural preferences for communication, non-monetary incentives, social preferences and social group identity.

We present the theoretical model and derive the predictions in Section 2. Section 3 describes the experimental design and procedures, while Section 4 presents the results. Finally, we discuss implications of our results in Section 5.

\section{Theory and Hypotheses}

\subsection{No Communication}

Consider a contest between two groups $A$ and $B$, each consisting of $N$ risk-neutral players. All players within each group simultaneously and independently expend irreversible and costly individual efforts $x_{i A}$ and $x_{i B}$. Players within the winning group each receive a prize $v$. Players within the losing group receive no prize. The total effective effort of each group depends on the lowest effort chosen by a member within the group - the so-called weakest-link. Group efforts determine winning probabilities using the Tullock (1980) lottery contest success function, so the probability of group $A$ (similarly group $B$ ) winning the prize is: ${ }^{3}$

$$
p_{A}\left(x_{i A}, x_{-i A}\right)=\frac{\min \left\{x_{1 A}, \ldots, x_{N A}\right\}}{\min \left\{x_{1 A}, \ldots, x_{N A}\right\}+\min \left\{x_{1 B}, \ldots, x_{N B}\right\}}
$$

The expected payoff for player $i$ in group $A$ (similarly group $B$ ) can be written as:

$$
\pi_{i A}\left(x_{i A}, x_{-i A}\right)=p_{A}\left(x_{i A}, x_{-i A}\right) v-x_{i A}
$$

The weakest-link rule for mapping individual efforts to group effort makes this a coordination game, with multiple pure-strategy Nash equilibria in which the players within the

\footnotetext{
${ }^{3}$ Groups win with equal probability if they both have a lowest effort equal to 0.
} 
same group match their efforts at the same level while each player best responds to the effort of all other players (Sheremeta, 2011; Cason et al., 2012; Lee, 2012; Brookins et al., 2015). The best-response functions (correspondences), defined by $x_{A} \leq \sqrt{x_{B} v}-x_{B}$ and $x_{B} \leq \sqrt{x_{A} v}-x_{A}$, are shown in Figure 1, and the full set of pure strategy Nash equilibria are illustrated by the double-shaded lens intersection of the two best-response functions. Thus in a treatment without any form of communication ( $\mathrm{NC}-\mathrm{NC})$, theory predicts that effort within each group shall be the same whereas across groups can vary between 0 and $v / 4$. The Pareto efficient equilibrium outcome is achieved when all players from both groups exert 0 effort and share the prize with equal probability. The least efficient equilibrium outcome is obtained when all players from both groups exert $v / 4$. This is the group Pareto dominant equilibrium because no group has an incentive to deviate from it.

\subsection{Symmetric Communication}

Next, consider a contest in which players within group $A$ and players within group $B$ can communicate. This corresponds to the $\mathrm{C}-\mathrm{C}$ treatment in the experiment. The results in existing literature indicate that the communicating groups usually act cooperatively as one player (Sutter and Strassmair, 2009; Zhang, 2009; Cason et al, 2012). ${ }^{4}$ Therefore, the contest between two groups reduces effectively to a contest between two unitary players, with groups choosing efforts according to the standard Tullock best-response functions $x_{A}=\sqrt{x_{B} v}-x_{B}$ and $x_{B}=\sqrt{x_{A} v}-x_{A}$ shown in Figure 2. Assuming that all players within each group act cooperatively results in the unique Nash equilibrium where all players in each group match their efforts at the same level, i.e., $x_{i A}=x_{A}=x_{j B}=x_{B}=v / 4$ for all $i$ and $j$. Note that this is exactly the same as the group

\footnotetext{
${ }^{4}$ One of the reasons why communication is such a powerful coordination device is that it creates group identity (Sutter, 2009; Cason et al, 2012). Chen and Li (2009) provide an excellent literature review and important new results on group identity.
} 
Pareto dominant equilibrium in the case with no communication. Thus, theory predicts that if communication indeed resolves within-group coordination problem and makes the communicating groups act as one player then allowing within-group communication may harm efficiency.

\subsection{Asymmetric Communication}

The new treatments introduced in this paper include exogenously imposed communication within one group and not the other (C-NC treatment), and the endogenous choice by each group to either establish communication or not (Endogenous treatment). This requires an analysis of communication asymmetry. Therefore, consider a contest in which players within group $A$ can communicate, while players in group $B$ cannot. This corresponds to the C-NC treatment. We maintain the assumption (supported in the previous empirical literature) that the communicating group $A$ acts as one player trying to jointly choose a common effort $x_{A}$, while all players in the non-communicating group $B$ maximize the objective function (2). Obviously, in any equilibria $x_{i A}=x_{A}$ for all $i$ and $x_{j B}=x_{B}$ for all $j$. If communication resolves coordination problem in group $A$, group $A$ will respond to the effort of group $B$ according to the best-response function $x_{A}=\sqrt{x_{B} v}-x_{B}$ (this is exactly the same best-response function as in a standard twoplayer Tullock contest). On the other hand, due to possible multiple coordination outcomes, players in group $B$ have a less precise best-response to the effort of group $A$, i.e. $x_{B} \leq \sqrt{x_{A} v}-$ $x_{A}$. The intersection of these best response functions provides the set of possible Nash equilibria as in Figure 3. Note that the set of Nash equilibria corresponds to the upward sloping part of the best response function of group $A$. 
Our theoretical model and resulting equilibria imply a number of testable hypotheses regarding the impact of asymmetric communication. The theoretical prediction for the C-NC treatment is that players in the non-communicating group should choose identical effort level between 0 and $v / 4$, and players within the communicating group should jointly maximize their payoffs in response to the behavior of the non-communicating group. As demonstrated in Figure 3, such best-response dictates higher effort level than the non-communicating group, although the range of possible efforts is still between 0 and $v / 4$. Therefore, regarding the effects of asymmetric communication, we expect the following:

Hypothesis 1: In the C-NC treatment, efforts of the communicating group are no smaller than efforts of the non-communicating group.

In the NC-NC treatment, all players within each group should coordinate on the same effort level, but this level can vary across groups between 0 and $v / 4$. The same is true for noncommunicating group in the $\mathrm{C}-\mathrm{NC}$ treatment, so we expect the following:

Hypothesis 2: Efforts of the non-communicating group in the C-NC treatment are similar to efforts of the non-communicating group in the NC-NC treatment.

In the $\mathrm{C}-\mathrm{C}$ treatment, all players within each group should choose efforts equal to the group Pareto dominant equilibrium of $v / 4$, and on average we documented earlier that average efforts modestly exceed this level. As illustrated in Figure 3, the equilibrium prediction for the communicating group in the $\mathrm{C}-\mathrm{NC}$ treatment lies in the range between 0 and $v / 4$, so this group should expend effort no greater than the communicating group in the $\mathrm{C}-\mathrm{C}$ treatment. Therefore, when comparing behavior in the $\mathrm{C}-\mathrm{NC}$ treatment to the $\mathrm{C}-\mathrm{C}$ treatment, we expect the following:

Hypothesis 3: Efforts of the communicating group in the C-NC treatment are no greater than efforts of the communicating group in the $\mathrm{C}-\mathrm{C}$ treatment. 
To summarize, we should observe the lowest aggregate effort in the NC-NC treatment, followed by the C-NC treatment, and then by the C-C treatment. Since lower efforts imply higher payoffs (due to the embedded contest structure), we should expect payoffs to be the highest in the NC-NC treatment, followed by the C-NC treatment, and then by the C-C treatment. Since efficiency is directly related to payoffs, we expect the same ranking for efficiency. This gives our final hypotheses regarding the impact of asymmetric communication:

Hypothesis 4: Payoffs and efficiency are the highest in the NC-NC treatment, followed by the C-NC treatment, and then by the C-C treatment.

\subsection{Endogenous Communication}

To study the effect of endogenous communication, we consider a contest in which group $A$ and group $B$ endogenously decide whether to establish within-group communication or not before making effort choices. We can derive a theoretical prediction for this Endogenous treatment by examining two cases. First, we determine if choosing to communicate is a dominant strategy given any effort choice of the other group when the other group chooses not to communicate. For this, we need to compare the expected payoff of the communicating group in the C-NC treatment to the expected payoff of the non-communicating group in the NC-NC treatment. If we assume that the behavior of the non-communicating group in the C-NC treatment is the same as the behavior of the non-communicating group in the NC-NC treatment, then the payoff of the communicating group in the C-NC treatment should be at least as great as the payoff of the non-communicating group in the NC-NC treatment (this is because the communicating group always best responds to the effort of the non-communicating group 
without having to deal with a coordination problem). ${ }^{5}$ Therefore, choosing to communicate is a weakly dominant strategy when the other group chooses not to communicate.

Second, we determine if choosing to communicate is a dominant strategy when the other group chooses to communicate. For this, we need to compare the expected payoff of the communicating group in the $\mathrm{C}-\mathrm{C}$ treatment and the expected payoff of the non-communicating group in the C-NC treatment. The payoff of the communicating group in the $\mathrm{C}-\mathrm{C}$ treatment is $v / 4$. The payoff of the non-communicating group in the $\mathrm{C}-\mathrm{NC}$ treatment is $\sqrt{x v}-x$ (i.e., $v x /(x+\sqrt{x v}-x)-x)$, where $x$ is any effort between 0 and $v / 4$ depending on the exact equilibrium selected. However, since $v / 4 \geq \sqrt{x v}-x$ for all $x$, choosing to communicate is a weakly dominant strategy. This gives our final hypotheses regarding the endogenous selection of communication.

Hypothesis 5: Groups should establish communication channels since choosing to communicate is a weakly dominant strategy.

It is interesting that by jointly choosing within-group communication both groups earn lower payoffs than by jointly choosing to restrict within-group communication (see Hypothesis 4). Therefore, the communication choice resembles a Prisoner's Dilemma game with a weakly dominant strategy.

\footnotetext{
${ }^{5}$ To make this point more clear, examine the following example. Assume that there are two 3-player groups and the prize value is 60 (these are the parameters that we use in our experiment). The prediction for the NC-NC treatment is that both non-communicating groups should coordinate by exerting efforts anywhere between 0 and 15 . Also, assume that in the NC-NC treatment, both groups actually choose 8 as their effort (which is very close to what we observe in our experiment). So, each player earns 22 (i.e., $60 \times 8 /(8+8)-8=22$ ). If the non-communicating group does not change its behavior in the $\mathrm{C}-\mathrm{NC}$ treatment, then the communicating group can increase its payoff by best responding to 8 and choosing 14 (i.e., $(8 \times 60)^{1 / 2}-8 \approx 14$ ). The corresponding payoff of the communicating group in the C-NC treatment is 24 (i.e., $60 \times 14 /(14+8)-14 \approx 24)$, which is higher than the payoff of the non-communicating group in the NC-NC treatment. Therefore, if the other group chooses not to communicate, choosing to communicate is a dominant strategy.
} 


\section{Experimental Design and Procedures}

Our principal research questions are about the impact of asymmetric and endogenous communication on competition between groups. To study these questions, we employed four treatments as summarized in Table 1: NC-NC, C-C, C-NC, and Endogenous. All treatments employed $N=3$ players in each group and all players within the winning group received the prize of $v=60$ experimental francs. Subjects were placed into group $A$ or $B$ at the beginning of the first period, and they stayed in the same group for the duration of the experiment. They also competed against the same opposing group for all 30 periods of their experimental session. We chose this fixed matching protocol to allow subjects an opportunity to coordinate with each other on one of the many different equilibria. Also, because of the fixed matching protocol we obtained a sufficient number of statistically independent observations to perform reasonably powerful non-parametric tests. ${ }^{6}$

At the beginning of each period, each subject received 60 experimental francs as an endowment (equivalent to \$2.00). Effort choices were framed in the instructions using the standard labels used in voluntary contribution mechanism public good provision experiments: they could allocate to a "group account" or an "individual account." The instructions informed subjects that by allocating 1 franc to their individual account they would earn 1 franc, while by allocating 1 franc to their group account they could increase the chance of their group receiving the reward. Subjects could contribute any integer number of francs between 0 and 60 .

The baseline treatment NC-NC implements a contest without communication. In treatments with communication, before subjects made their allocation decisions they had an

\footnotetext{
${ }^{6}$ Subjects were informed that the session would last for exactly 30 periods, so the stage equilibrium prediction also holds for this finitely repeated game. As noted above, we conjectured that groups or individuals might coordinate on Pareto-improving outcomes in the repeated game, since this is frequently observed in the experimental literature even in finitely-repeated games with a unique equilibrium (e.g., Selten and Stoecker, 1986).
} 
opportunity to communicate with other participants via chat windows. In the C-NC treatment, subjects in one group could send messages to the two other members of their own group anonymously via this chat window for 60 seconds each period. In the C-C treatment, separate chat windows were enabled for both groups. For all chat communications we asked subjects to follow two basic rules: (i) to be civil to one another and not to use profanity, and (ii) not to identify themselves in any manner. Messages were recorded. After the chat period was over, all subjects simultaneously made their effort (allocation) decisions, and then a random draw determined the winning group. A simple lottery was used to explain how the computer chose the winning group. ${ }^{7}$ At the end of each period subjects were informed of group $A$ 's and $B$ 's effective efforts (i.e., the minimum effort in each group).

Note, in the above three treatments, we exogenously vary the communication channel to measure the causal effect of symmetric and asymmetric communication in the competitive coordination game. To further explore whether these effects persist when groups can endogenously choose to enable or disable communication, we implement an endogenous communication treatment as follows. All subjects began with 10 periods of the NC-NC treatment to become familiar with the strategic properties of the game. Then three players in each group voted (before period 11 and before period 21) whether to establish communication for 10 periods. ${ }^{8}$ Unanimity was required to establish communication channel. After the voting stage, the computer revealed whether each group elected to communicate during the competition stage. Therefore, effectively groups could endogenously choose to participate in the NC-NC, C-C, or

\footnotetext{
${ }^{7}$ Probabilities were explained in the instructions as a number of tokens placed in a bingo cage based on effort choices, and then one token draw determined the winning individual or group.

${ }^{8}$ Another option was to allow subjects to vote every round to decide whether they want to communicate or not. However, it would substantially delay the experiment (by about an hour) and it would also create incentives for subjects to avoid lengthy communications. Another concern is that after subjects choose to communicate after period 10 (i.e., they end up in the $\mathrm{C}-\mathrm{NC}$ or $\mathrm{C}-\mathrm{C}$ treatment), they can devise a future strategy in case when such communication is not available. However, reading through chats we did not find this to be the case.
} 
C-NC treatment. ${ }^{9}$ We considered alternative ways of implementing endogenous communication, such as including explicit costs of opening chat rooms or more frequent votes to open or close communication opportunities. We chose this 10-period time frame for stationary communication subgames to strengthen the importance of the communication votes and to reduce potential spillovers across periods arising from group planning in communication periods for strategies in non-communication periods (Isaac and Walker, 1991).

The experiment was conducted at the Vernon Smith Experimental Economics Laboratory. A total of 216 subjects participated in 18 sessions. Subjects were Purdue University undergraduate students who participated in only one session of this study. Some students had participated in other economics experiments that were unrelated to this research. Data from the 96 subjects in the NC-NC and C-C treatments were previously reported in Cason et al. (2012) as the "NOCOMM" and "INTRA" treatments. Results from the additional 120 subjects in the asymmetric and endogenous communication treatments are newly reported in this study.

The computerized experimental sessions were run using z-Tree (Fischbacher, 2007). At the beginning of each session subjects were given the written instructions, shown in Appendix, and the experimenter also read the instructions aloud. At the end of the session, 5 out of 30 randomly-drawn periods were selected for payment. Earnings were converted from experimental francs into US dollars at a preannounced exchange rate. Subjects earned about $\$ 21$ on average and sessions lasted about 60 to 90 minutes.

\footnotetext{
${ }^{9}$ As we expect that people have a natural tendency to communicate, we adopted a very strict voting rule - groups must reach a unanimous decision in a single vote to open the communication channel to increase the occurrence of the endogenous C-NC treatment. It turned out that among the 72 subjects, only 7 subjects voted against communication in the first voting round and they belonged to 7 different groups. Thus if we had used a majority rule, we would only observe the endogenous $\mathrm{C}$-C treatment. The second vote before period 21 gives groups another chance to decide whether they want to communicate. It could provide perhaps the clearest evidence of the desirability of communication if groups switched from communication to no-communication.
} 


\section{Experimental Results}

\subsection{Exogenous Communication}

The first part of Table 2 summarizes the average group effective (minimum) effort, individual effort, wasted effort, and expected payoffs (based on effort choices, before the lottery draw) in the three exogenous treatments. Figure 4 displays the effective group effort over time by treatment. In the NC-NC treatment, average individual effort should be between 0 and 15 . The actual average effort is 11.18 , indicating that subjects learn to coordinate their efforts on substantial level. When within-group communication is allowed in both groups, as in the C-C treatment, the average individual effort is 20.13. Both the average and minimum (group effective) efforts are significantly higher in the C-C treatment than in the NC-NC treatment (Mann-Whitney test, $p$-value $<0.05, n=m=8$ ). ${ }^{10}$ Also, we find that the amount of wasted effort is significantly lower in the C-C treatment than in the NC-NC treatment (Mann-Whitney test, $p$ value $<0.05 ; n=m=8) .{ }^{11}$ Most importantly, because of the greater efforts in the C-C treatment, the expected payoff in the C-C treatment is significantly lower than the payoff in the NC-NC treatment (Mann-Whitney test, $p$-value $<0.05, n=m=8$ ). These results have been previously reported in Cason et al. (2012) and they serve as a baseline for examining how asymmetric communication impacts behavior in competitive coordination games.

In the novel C-NC treatment, within-group communication was allowed only in one group. Our hypothesis is that because of communication efforts of the communicating group should be no lower than efforts of the non-communicating group. Table 2 shows that in the communicating group the actual average individual effort is 13.99 and the average group

\footnotetext{
${ }^{10}$ All non-parametric tests employ only the independent observations of six subjects. Similar results hold when considering only the later 20 periods.

${ }^{11}$ Wasted effort is calculated by taking the average of the differences between individual effort and the group minimum effort within each group (Riechmann and Weimann, 2008). Complete coordination is reached when wasted effort equals zero.
} 
effective (minimum) effort is 13.56. In the non-communicating group the average individual effort is 11.30 and effective effort is 8.85 . Consistent with Hypothesis 1, both effort measures are significantly different between the communicating and non-communicating groups (Wilcoxon signed-rank test, $p$-value $=0.02, n=8)$. Also, relative to the non-communicating group, the communicating group in the $\mathrm{C}-\mathrm{NC}$ treatment achieves significantly better coordination (the mean wasted effort is 0.43 versus 2.45; Wilcoxon signed-rank test, $p$-value<0.01, $n=8) .{ }^{12}$ The communicating group attributed their superior ability to coordinate and make higher efforts to their chats. In their own words, "i bet we'd be dumb like them if we couldn't talk"; "we r dominating. still do 5 cuz they're not changing"; "team work is good".

Result 1: In the C-NC treatment, the communicating group expends higher effort and achieves better coordination than the non-communicating group.

Comparing treatments $\mathrm{NC}-\mathrm{NC}$ and $\mathrm{C}-\mathrm{NC}$, the non-communicating groups in both treatments behave very similarly. In particular, in the NC-NC treatment, the average individual effort is 11.18 , the minimum effort is 8.29 , and the wasted effort is 2.89 . Similarly, in the C-NC treatment, the average individual effort of the non-communicating group is 11.30 , the minimum effort is 8.85 , and the wasted effort is 2.45 . For each of these measures, the differences are not significant between the two treatments, providing support for Hypothesis 2.

Result 2: The non-communicating group in the C-NC treatment expends similar effort and achieves similar coordination than the non-communicating group in the NC-NC treatment.

Comparing treatments $\mathrm{C}-\mathrm{NC}$ and $\mathrm{C}-\mathrm{C}$, the communicating group in the $\mathrm{C}-\mathrm{NC}$ treatment expends significantly lower effective effort than the communicating group in the $\mathrm{C}-\mathrm{C}$ treatment (13.56 versus 18.86; Mann-Whitney test, $p$-value $=0.02, n=m=8$ ). This finding is consistent with Hypothesis 3. Interestingly, we also find that the communicating group in the $\mathrm{C}$-NC treatment

\footnotetext{
${ }^{12}$ As with other results summarized here, conclusions are unchanged if only later periods are analyzed.
} 
achieves better coordination than the communicating group in the $\mathrm{C}-\mathrm{C}$ treatment (the mean wasted effort is 0.43 versus 1.27; Mann-Whitney test, $p$-value $=0.01, n=m=8$ ).

Result 3: The communicating group in the C-NC treatment expends lower effort and achieves better coordination than the communicating group in the $\mathrm{C}-\mathrm{C}$ treatment.

Our next hypothesis concerns how asymmetric communication impacts payoffs. Previous studies have shown that allowing within-group communication leads to better coordination, but as a result it can also lead to more aggressive competition and lower efficiency (Cason et al., 2012). Our hypothesis, based on theoretical analysis, is that asymmetric communication should have a less dramatic impact on payoffs and efficiency. This is because the non-communicating group cannot compete more aggressively due to the lack of a communication channel. We have previously documented that the expected payoff in the NC-NC treatment is significantly higher than the payoff in the $\mathrm{C}-\mathrm{C}$ treatment (18.82 versus 9.87; Mann-Whitney test, $p$-value $<0.05$, $n=m=8$ ). When examining the impact of asymmetric communication relative to symmetric communication, we find that the payoff of the communicating group in the C-NC treatment is significantly higher than the payoff in the C-C treatment (22.71 versus 9.87; Mann-Whitney test, $p$-value $<0.05, n=m=8$ ), while the payoff of the non-communicating group in the C-NC treatment is not significantly different from the payoff in the C-C treatment (12.01 versus 9.87; MannWhitney test, $p$-value $=0.60, n=m=8$ ). This suggests that, consistent with Hypothesis 4 , the asymmetric communication has a less dramatic impact on payoffs and efficiency. When examining the impact of asymmetric communication relative to no communication, we find that the payoff of the communicating group in the C-NC treatment is not significantly different from the payoff in the NC-NC treatment (22.71 versus 18.82 ; Mann-Whitney test, $p$-value $=0.34$, $n=m=8$ ), while the payoff of the non-communicating group in the C-NC treatment is 
significantly lower than the payoff in the NC-NC treatment (12.01 versus 18.82; Mann-Whitney test, $p$-value $<0.05, n=m=8$ ). In general, our results are consistent with Hypothesis 4 .

Result 4: The communicating group in the C-NC treatment earns higher payoffs than the communicating group in the $\mathrm{C}-\mathrm{C}$ treatment and similar payoffs to the non-communicating group in the NC-NC treatment. The non-communicating group in the C-NC treatment earns similar payoffs to the communicating group in the $\mathrm{C}-\mathrm{C}$ treatment and lower payoffs than the noncommunicating groups in the NC-NC treatment.

To summarize, within-group communication causes groups to compete more aggressively. When only one group can communicate, the communicating group coordinates better and expends higher efforts than the non-communicating group. However, the communicating group earns payoffs that are similar to the baseline contest without communication, while the non-communicating group earns lower payoffs than in the baseline, non-communication contest. Allowing within-group communication in both groups leads to even more aggressive competition and the lowest payoffs to both groups. Therefore, it appears that although asymmetric within-group communication is not as harmful as symmetric communication, it leads to more aggressive competition and lower efficiency relative to the case when no groups can communicate.

\subsection{Endogenous Communication}

Given that communication harms efficiency, do groups still choose to establish the "harmful" communication channel? To answer this question, we examine behavior of 24 groups in the Endogenous treatment. Table 3 summarizes the endogenous communication choices by periods. In periods 1-10 all 24 groups were assigned exogenously to the NC-NC treatment and 
were not allowed to communicate. Before period 11, members of each group voted whether to open the communication channel for periods 11-20. Overall, 65 out of 72 participants voted to open the channel of communication within their groups, resulting in 17 out of 24 groups having the ability to communicate during periods $11-20 .{ }^{13}$ Consequently, 2 groups participated in the NC-NC treatment, 12 groups in the C-C treatment and 10 groups in the $\mathrm{C}-\mathrm{CN}$ treatment. Before period 21, members of each group voted again to open the communication channel for periods 21-30. This time, 68 out of 72 participants voted to communicate within their groups, resulting in 20 out of 24 groups having the ability to communicate during periods $21-30 .{ }^{14}$ Consequently, no groups participated in the NC-NC treatment, 16 groups in the $\mathrm{C}-\mathrm{C}$ treatment and 4 groups in the C-CN treatment. ${ }^{15}$ Therefore, it appears that the vast majority of participants, and consequently groups, endogenously choose to have continued access to communication. This result is consistent with our final Hypothesis 5.

Result 5: The vast majority of groups endogenously and consistently choose to have access to communication.

Do groups that choose to communicate endogenously behave differently than groups that are allowed to communicate exogenously? Figure 5 visually shows the comparison between

\footnotetext{
${ }^{13}$ Looking at the data from periods 1-10, we did not find any significant difference in group effort, wasted effort and payoffs between the 7 groups that voted against communication and the 17 groups that voted for communication. Given that communication is costless and groups have not yet experienced the potential harmful effect of communication, it is puzzling why these 7 subjects chose not to communicate.

${ }^{14}$ Three out of 7 subjects who voted against communication in the first vote continued choosing not to communicate in the second vote. The 4 groups that switched to communication in second vote all earned less than their opponent groups during periods 11-20.

15 Only 1 of the 17 groups who communicated in periods 11-20 chose not to communicate in periods 21-30. This group faced very aggressive competition from the opponent group after communication was enabled and raised average effort from about 9 tokens in the first 10 periods to an average of 27.8 (compared to 22.3 by their opponent) in the second 10 periods. Although their average effort was higher than the opponent group, they only won $40 \%$ of the time. In this group, members expressed frustration via chat in period 19 [session 120827_1512, group 2]: "ID6: sad...." "ID 5: we have lost the last 3"; "ID 4: yeah they have had better odds luck". In period 20, ID 5 put in 0 tokens deviating from the proposal of "ok do 34 again". Perhaps as a result of this deviation, ID 6 voted against communication in period 21. Their opponent group who continued to communicate commented in period 21: "they don't communicate lol" "I know" "lol" "stupids" "and put 0 lol" "lets keep this going" "they lose the advantage".
} 
behavior in the Endogenous and exogenous communication treatments. ${ }^{16}$ For average effort, no significant differences exist between NC-NC and en_NC-NC (8.2 versus 8.4; Mann-Whitney test, $p$-value $=0.97, n=8, m=12)$, between C-C and en_C-C (18.9 versus 20.3; Mann-Whitney test, $p$ value $=0.34, n=8, m=9$ ), between non-communicating groups in C-NC and en_C-NC ( 8.9 versus 11.1; Mann-Whitney test, $p$-value $=0.35, n=8, m=7$ ), and between communicating groups in CNC and en_C-NC (14.1 versus 13.3; Mann-Whitney test, $p$-value=0.73, $n=8, m=7$ ). Thus, it appears that what matters is the type of the communication channel, not whether the specific channel is created exogenously or endogenously. Groups that endogenously choose to communicate expend similar efforts than groups that are allowed to communicate exogenously.

Similarly, we find no statistical differences between the average wasted effort in the Endogenous treatment and exogenous treatments (all $p$-values are greater than 0.10$).{ }^{17}$ The same is true when comparing the average payoffs (all $p$-values are greater than 0.10 ).

Result 6: Groups that endogenously choose to communicate expend similar efforts, achieve similar coordination and earn similar payoffs than groups that are allowed to communicate exogenously.

Note that as with exogenous communication, endogenously chosen within-group communication makes groups compete more aggressively. The competition level is moderate and payoffs are the highest when no group chooses to communicate. When only one group chooses to communicate, the competition level increases and payoffs decrease for the non-

\footnotetext{
${ }^{16}$ Recall, in the Endogenous treatment, groups were not allowed to vote to open the communication channel until period 11. There was only one pair of groups each endogenously chose not to communicate in periods 11-20 and no pair in periods 21-30. We report the data from periods 1-10 for the NC-NC outcome in endogenous treatment (the first blue bar in the figure). All other comparisons use data from periods 11-30.

${ }^{17}$ The only exception is the comparison between communicating groups in C-NC and en_C-NC (0.3 versus 1.3; Mann-Whitney test, $p$-value $=0.07, n=8, m=7$ ).
} 
communicating group. Finally, when both groups choose to communicate this leads to the most aggressive competition and the lowest payoffs to both groups.

To further explore the effects of communication and find out why communication is harmful, we analyze how subjects utilize communication and use content analysis to examine what kinds of messages are associated with more competitive behavior.

\subsection{Analysis of Communication Content}

The analysis of communication content is challenging because the qualitative information exchanged in chats is difficult to quantify objectively. The procedure that we used is becoming standard in the emerging experimental economics literature that explicitly analyzes how chat communication affects behavior. First, we randomly selected a session to develop a coding scheme. A careful analysis of messages in that session resulted in 16 independent categories

shown in Table 4. Then we employed two individuals to code independently all chat room discussions into the coding categories. The unit of observation for coding was all messages in a given period within each chat room. If that chat room was deemed to contain the relevant category of content for that period it was coded as 1 for that category and 0 otherwise. Each unit was coded under as many or few categories as the coders deemed appropriate. The coders were not informed about any hypotheses of the study, although they read the experiment instructions provided to subjects so that they understood the strategic environment the subjects faced.

Coding is subjective so the coders do not always agree on the message classification. To assess whether a particular type of message meaning is reliably coded, we follow HenningSchmidt et al. (2008) and Cooper and Kühn (2014) in using a standard approach from content analysis methodology to adjust the reliability statistic to account for the number of categories 
that coders can use for classification. Agreement between the coders can occur by chance, especially if there are few categories for classification or that type of content is very frequently or infrequently observed. Cohen's Kappa (Krippendorff, 2004; Cohen, 1960) is a scaled measure of agreement that takes a value of 0 when the agreement is consistent with random chance and 1 when the coders agree perfectly. Kappa values between 0.41 and 0.60 are considered "Moderate" agreement, and those above 0.60 indicate "Substantial" agreement (Landis and Koch, 1977). Most of our message categories were coded at the "Moderate" or "Substantial" agreement. Some categories that were classified below the threshold of 0.4 , as indicated by italic in Table 4 , were excluded from analysis.

Table 4 displays the average frequency that the coders classified chat room discussions in specific categories. In all treatments, the most common category coded is "agreement reached within group" (category $C 2 a$ ), suggesting that $76 \%-92 \%$ of time group members coordinate by reaching agreement. Also, a considerable fraction of coded chat rooms $(30 \%-40 \%)$ include discussions about using the same strategy over time, i.e., subjects want to "stick with the same strategy" (category $C 2 g$ ). The fact that subjects often reach agreement and coordinate on a specific strategy is consistent with Results 1 and 3, which document that within-group communication improves coordination.

Another category that is frequently coded (17\%-38\%) is about competition - subjects use messages to encourage competition and to evoke a desire to win the contest, i.e., "try to win/compete by raising effort" (category $C 2 d$ ). Finally, it appears from chat messages that subjects use Cournot belief updating (20\%-38\%), i.e., they "look back one period" (category Cla), and they take into account the behavior of other group members $(16 \%-38 \%)$, i.e., they "make choices by reasoning from the other group's point of view" (category C1c). These 
observations suggest that when examining how communication impacts effort in contests, it is important to control for learning, Cournot updating, and behavior of the opponents.

Table 5 reports estimation results of random effects models of individual effort choices $\left(\right.$ Effort $\left._{t}\right)$ on previous period effort chosen by the competing group (Othergroup-effort $\left.t_{t-1}\right)$ and the previous period effort squared (Othergroup-effort $t_{t-1} \wedge 2$ ), to account for the inverted U-shaped best response reaction function illustrated in Figures 1-3. These models also control for the risk attitudes inferred from the separate lottery choice task (Risk), the effective effort chosen by that group in the previous period (Group-effort $\left.t_{t-1}\right)$ and a nonlinear time trend (1/period). ${ }^{18}$ Finally, all regressions are augmented with the reliably-coded categories of communication from Table 4.

The estimate on Group-effort $t_{t-1}$ is positive and significant in all treatments and data subsets, suggesting that individuals learn to coordinate their individual effort to match their group effort. The estimate on Messages is positive and significant in the Endogenous treatment (columns 3 and 4), indicating that the more messages subjects send in the Endogenous treatment the more aggressive is their effort expenditure. In some treatments the estimates on categories $C 1 a, C 1 b$, and $C 1 c$ are significant, suggesting that subjects are learning to best respond to the actions of others. In almost all cases the estimates on categories $C 2 c$ and $C 2 d$ are significant but with opposite signs. This is intuitive: the more subjects send messages about cooperation (category $C 2 c$ ) the lower is their effort and the more subjects send messages expressing their desire to compete and win (category $C 2 d$ ) the higher is their effort. Table 4 shows that there are

\footnotetext{
${ }^{18}$ Before the subjects played 30 periods of the stage game, we elicited subjects' risk attitudes using multiple price list of 15 simple lotteries, similar to Holt and Laury (2002). Specifically, subjects were asked to state whether they preferred safe option A or risky option B. Option A yielded $\$ 1$ payoff with certainty, while option B yielded a payoff of either $\$ 3$ or $\$ 0$. The probability of receiving $\$ 3$ or $\$ 0$ varied across all 15 lotteries. The first lottery offered a $0 \%$ chance of winning $\$ 3$ and a $100 \%$ chance of winning $\$ 0$, while the last lottery offered a $70 \%$ chance of winning $\$ 3$ and a 30\% chance of winning $\$ 0$. At the end of the session, one of the 15 lottery decisions was randomly selected for payment. Overall, $74 \%$ of the subjects are risk averse in both the exogenous and endogenous treatments. Theoretically it is not clear how risk aversion may impact individual behavior in our game. However, most studies find that in simple lottery contests more risk-averse subjects choose lower efforts than less risk-averse subjects (Sheremeta and Zhang, 2010; Shupp et al., 2013; Dechenaux et al., 2015).
} 
almost twice as many messages about competition and winning (category $C 2 c$ ) than about cooperation (category $C 2 d$ ). The fact that subjects spend so many messages emphasizing competition and winning may help explaining why communication makes groups compete more aggressively. Finally, note that verbal bullying or punishment (category $C 4 a$ ) is associated with much greater effort. This suggests that these types of statements, while used infrequently, can restore higher efforts and promote the aggressive competition seen in the presence of communication.

\section{Discussion}

Recent research has shown that allowing within-group communication in competitive coordination games, such as rent-seeking contests, may lead to more aggressive competition between groups and lower efficiency. This study further explores potentially harmful effects of communication in competitive coordination games, by addressing the questions of (i) asymmetric communication and (ii) the endogenous emergence of communication. Our theoretical analysis provides testable hypotheses regarding the effect of communication on competitive behavior and efficiency. We test these predictions using a laboratory experiment. The experiment shows that although asymmetric communication is not as harmful as symmetric communication, it leads to more aggressive competition and lower efficiency relative to the case when neither group can communicate. We use content analysis to analyze why communication is harmful and find that subjects often send messages expressing their desire to compete and win. Moreover, such messages are positively and significantly correlated with effort expenditures in the contest. These types of communication patterns can help explain overly aggressive competition in the presence of communication. The experiment also reveals that despite the 
"harmful" effect of communication, groups endogenously and consistently choose to communicate even though they would earn higher payoffs if jointly they chose to restrict withingroup communication.

The results of our experiment indicate that both groups can increase their payoffs by restricting within-group communication. However, the question is why groups, instead of restricting their communication channel, choose to communicate, thus aggravating competition, lower payoffs and lowering efficiency?

One possible explanation is that groups simply behave strategically. Choosing to communicate or not resembles a Prisoner's Dilemma game with a weakly dominant strategy. However, there are many experimental studies, such as studies of the second-price sealed bid auction, showing that the weakly dominant strategy is not a good predictor of individual behavior (Camerer, 2003). Given that we find almost unanimous choice of a weakly dominant strategy to communicate, we believe that besides purely strategic reasons, there may be other reasons for such strong adoption of communication in our experiment.

First, it is possible that the desire to communicate is hard-wired into people. Researchers in communication studies identify several reasons why people communicate: people communicate to engage and persuade others, to seek and provide information, and to express emotions like frustration, joy, or disappointment. Especially when people face tasks that involve conflicts and competition, communication is one of the most sought-after ways to settle conflict (Cragan and Wright, 1990). In our experiment, in the vast majority of cases all three group members are engaged in communication by sending messages and on average each subject sends about 2-3 message lines in a given communication period. Communication is used effectively to 
coordinate own member's efforts to compete against the opponent group. Moreover, subjects mainly express positive attitude regarding the opportunity to communicate (see Table 4).

Second, it is possible that subjects' objectives are not only monetary. Sheremeta (2010) finds that subjects are willing to incur monetary costs to be announced as winners ${ }^{19}$ Others find that status may be important (Kosfeld and Neckermann, 2011; Charness et al., 2014). Similarly, we find that subjects frequently talk about winning and such messages lead to more aggressive competition. In some cases the chat messages indicate that subjects are willing to forgo payoffs for the joy of winning: "we might earn 10 francs less, but we can increase chances of winning". Therefore, if winning is a component of individual utility, then subjects, who may even be perfectly aware of harmful effects of communication, may still choose to communicate in order to increase their utility of winning. ${ }^{20}$

Third, related to the non-monetary incentives argument is the idea that instead of maximizing individual payoff, a subject may want to maximize his/her payoff relative to the opponent's payoff (Fehr and Schmidt, 1999). Indeed, some studies provide evidence for such behavior in contests (Mago et al., 2016; Sheremeta, 2016). Therefore, choosing to communicate can be a strictly dominant strategy, since communicating group in the $\mathrm{C}-\mathrm{NC}$ treatment receives higher payoff than the non-communicating group.

Finally, it is possible that communication increases saliency of group identity (Chen and Li, 2009; Sutter, 2009), and subjects may prefer to communicate in order to strengthen their group identity. Messages that highlight collective group goals and common group identity, strengthen group-based norms and manipulate the perceptions of the in-group and out-group are

\footnotetext{
${ }^{19}$ This finding has been replicated by Price and Sheremeta (2011, 2015), Brookins and Ryvkin (2014) and Mago et al. (2016).

${ }^{20}$ Indeed, we find that in the C-NC treatment, the communicating group wins significantly more often than the noncommunicating group.
} 
often observed in our experiment (e.g., "don’t be selfish" "our group rocks"; "wow group b is stupid”; “.it was good working with you guys").

In short, there are many strategic and nonstrategic reasons to choose to communicate in the competitive coordination game. To mitigate the efficiency-reduction effect due to the endogenous emergence of communication, one possible way is to make communication costly. There are several papers exploring the effect of costly endogenous communication on coordination (Andersson and Holm, 2010, 2013; Kriss et al., 2014). The main message from this small literature is that efficient coordination is reduced because people choose to communicate too little even when the communication costs are small relative to the communication gain. This could be due to factors such as bounded rationality (Dietrichson and Jochem, 2014). In our environment, charging a fee to communicate may make subjects to communicate less often for both strategic and nonstrategic reasons.

Theoretically, the choice of whether to open a costly communication channel depends on the expectation of what equilibrium will be selected in the group contest. Recall, that there are multiple equilibria in the second stage, which vary in terms of expected payoffs. If a player expects that the other group is going to exert a small amount of effort in the contest stage, then this player should be willing to pay some amount of money in order to coordinate with her group and best-respond to the competing group. Gains to cooperation differ as beliefs vary. Besides this strategic consideration, some subjects may be willing to incur monetary costs simply to be announced as winners, and some subjects may have rivalistic preferences in contests. The increased utility of winning due to better coordination through communication, or utility gains from earning more than others, can more than compensate for the decreased utility of monetary payoffs due to the small cost of communication. If these motivations are salient, subjects may 
still choose to communicate. It is an interesting empirical question to examine whether and how big the communication cost needs to be in order to deter groups from communicating, which in turn, could increase efficiency in the competitive coordination game.

This experiment implemented the classical Tullock model of rent-seeking, which has been widely used to model incentives for competing interest groups to influence public policy. While more confident conclusions await further research, we can note preliminary implications of our results for this setting. In particular, our findings indicate that both symmetric and asymmetric within-group communication results in greater wasteful rent-seeking. Future research can investigate how robust our findings are when the best-shot or summation (perfectsubstitutes) technology is used within groups instead of the weakest-link effort aggregation rule (Abbink et al., 2010; Sheremeta, 2011; Leibbrandt and Sääksvuori, 2012; Chowdhury et al., 2013). Drawing on results from Sutter and Strassmair (2009) and Sheremeta (2011), we conjecture that other mechanisms to aggregate individual efforts into group contests would also result in increased efforts when groups can communicate. Our general conjecture is that in group rent-seeking contests, similar to the one studied in this paper, mechanisms such as communication that lead to better within-group coordination will reduce efficiency. 


\section{References}

Abbink, K., Brandts, J., Herrmann, B., \& Orzen, H. (2010). Inter-group conflict and intra-group punishment in an experimental contest game. American Economic Review, 100, 420-447.

Ahn, T.K., Isaac, R.M., \& Salmon, T.C. (2011). Rent seeking in groups. International Journal of Industrial Organization, 29, 116-125.

Andersson, O., \& Holm, H. (2010). Endogenous communication and tacit coordination in market entry games - an explorative experimental study. International Journal of Industrial Organization 28, 477-495.

Andersson, O., \& Holm, H. (2013). Speech is silver; silence is golden. Games, 4, 497-507.

Blume, A., \& Ortmann, A. (2007). The effects of costless pre-play communication: Experimental evidence from games with Pareto-ranked equilibria. Journal of Economic Theory, 132, 274290.

Brandts, J., \& Cooper, D. (2007). It's what you say, not what you pay: An experimental study of manager-employee relationships in overcoming coordination failure. Journal of the European Economic Association, 5, 1223-1268.

Brookins, P., \& Ryvkin, D. (2014). An experimental study of bidding in contests of incomplete information. Experimental Economics, 17, 245-261.

Brookins, P., Lightle, J. P., \& Ryvkin, D. (2015). The effects of communication and sorting on output in heterogeneous weak-link group contests. Working Paper.

Camerer, C. (2003). Behavioral game theory: Experiments in strategic interaction. Princeton University Press.

Cason, T.N., Sheremeta, R.M., \& Zhang, J. (2012). Communication and efficiency in competitive coordination games. Games and Economic Behavior, 76, 26-43.

Charness, G. (2000). Self-serving cheap talk: A test of Aumann's conjecture. Games and Economic Behavior, 33, 177-194.

Charness, G., \& Grosskopf, B. (2004). What makes cheap talk effective? Experimental evidence. Economics Letters, 83, 383-389.

Charness, G., Masclet, D., \& Villeval, M.C. (2014). The dark side of competition for status. Management Science, 60, 38-55.

Chen, Y. \& Li, X. (2009). Group identity and social preferences. American Economic Review, 99, 431-457.

Chowdhury, S.M., Lee, D., \& Sheremeta, R.M. (2013). Top guns may not fire: Best-shot group contests with group-specific public good prizes. Journal of Economic Behavior and Organization. 92, 94-103.

Clark, D.J., \& Konrad, K.A. (2007). Asymmetric conflict: Weakest link against best shot. Journal of Conflict Resolution, 51, 457-469.

Cohen, J. (1960). A coefficient of agreement for nominal scales. Educational and Psychological Measurement, 20, 37-46.

Cooper, D.J., \& Kühn, K.U. (2014) Communication, renegotiation, and the scope for collusion, American Economic Journal: Microeconomics, 6, 247-278.

Cooper, R., De Jong, D., Forsythe, R., \& Ross, T. (1992). Communication in coordination games. Quarterly Journal of Economics, 107, 739-771.

Cragan, J.F., \& Wright, D.W. (1991). Communication in small group discussions: An integrated approach (3rd edition). St. Paul, MN: West. 
Dechenaux, E., Kovenock, D., \& Sheremeta, R.M. (2015). A survey of experimental research on contests, all-pay auctions and tournaments. Experimental Economics, 18, 609-669.

Deck, C., \& Sheremeta, R.M. (2012). Fight or flight? Defending against sequential attacks in the game of Siege. Journal of Conflict Resolution, 56, 1069-1088.

Dietrichson, J. \& Jochem, T. (2014). Organizational coordination and costly communication with boundedly rational agents. Working paper.

Duffy, J., \& Feltovich, N. (2002). Do actions speak louder than words? Observation vs. cheap talk as coordination devices. Games and Economic Behavior, 39, 1-27.

Duffy, J., \& Feltovich, N. (2006). Words, deeds and lies: Strategic behavior in games with multiple signals. Review of Economic Studies, 73, 669-688.

Eisenkopf, G. (2014). The impact of leadership incentives in intergroup contests. European Economic Review, 67, 42-61.

Fehr, E., \& Schmidt, K.M. (1999). A theory of fairness, competition, and cooperation. Quarterly Journal of Economics, 114, 817-868.

Fischbacher, U. (2007). Z-Tree: Zurich toolbox for ready-made economic experiments. Experimental Economics, 10, 171-178.

Henning-Schmidt, H., Li, Z.Y., \& Yang, C. (2008). Why people reject advantageous offers non-monotonic strategies in ultimatum bargaining: Evaluating a video experiment run in PR China. Journal of Economic Behavior and Organization, 65, 373-384.

Hirshleifer, J. (1983). From weakest link to best-shot: The voluntary provision of public goods. Public Choice, 41, 371-386.

Holt, C.A., \& Laury, S.K. (2002). Risk aversion and incentive effects. American Economic Review, 92, 1644-1655.

Isaac, R.M., \& Walker, J. (1991). Costly communication: An experiment in a nested public goods problem. In Contemporary Laboratory Research in Political Economy, T. Palfrey (Ed.). Ann Arbor, MI: Univ. of Michigan Press.

Kosfeld, M., \& Neckermann, S. (2011). Getting more work for nothing? Symbolic awards and worker performance. American Economic Journal: Microeconomics, 3, 86-99.

Krippendorff, K. (2004). Content analysis: An introduction to its methodology, Sage Publications: Thousand Oaks, CA.

Kriss, P.H., Blume, A., \& Weber, R. (2014). Organizational coordination with decentralized costly communication. Working Paper.

Landis, J.R., \& Koch, G. (1977). An application of hierarchical Kappa-type statistics in the assessment of majority agreement among multiple observers. Biometrics, 33. 363-374.

Lee, D. (2012). Weakest-link contests with group-specific public good prizes. European Journal of Political Economy, 28, 238-248.

Leibbrandt, A., \& Sääksvuori, L. (2012). Communication in intergroup conflicts. European Economic Review, 56, 1136-1147.

Mago, S.D., Savikhin, A.C., \& Sheremeta, R.M. (2016). Facing your opponents: Social identification and information feedback in contests. Journal of Conflict Resolution, 60, 459481.

Price, C.R., \& Sheremeta, R.M. (2011). Endowment effects in contests. Economics Letters, 111, 217-219.

Price, C.R., \& Sheremeta, R.M. (2015). Endowment origin, demographic effects and individual preferences in contests. Journal of Economics and Management Strategy, 24, 597-619. 
Riechmann, T., \& Weimann J. (2008). Competition as a coordination device: Experimental evidence from a minimum effort coordination game. European Journal of Political Economy, 24, 437-454.

Selten, R., \& Stoecker, R. (1986). End behavior in sequences of finite Prisoner's Dilemma supergames: A learning theory approach. Journal of Economic Behavior and Organization, 7, 47-70.

Sheremeta, R.M. (2011). Perfect-substitutes, best-shot, and weakest-link contests between groups. Korean Economic Review, 27, 5-32.

Sheremeta, R.M. (2013). Overbidding and heterogeneous behavior in contest experiments. Journal of Economic Surveys, 27, 491-514.

Sheremeta, R.M. (2016). Impulsive behavior in competition: Testing theories of overbidding in rent-seeking contests. Working Paper.

Sheremeta, R.M. (2017). Behavior in group contests: A review of experimental research. Working Paper.

Sheremeta, R.M., \& Zhang, J. (2010). Can groups solve the problem of over-bidding in contests? Social Choice and Welfare, 35, 175-197.

Shupp, R., Sheremeta, R.M., Schmidt, D., \& Walker, J. (2013). Resource allocation contests: Experimental evidence. Journal of Economic Psychology, 39, 257-267.

Sutter, M. (2009). Individual behavior and group membership: Comment. American Economic Review, 99, 2247-2257.

Sutter, M., \& Strassmair, C. (2009). Communication, cooperation and collusion in team tournaments - An experimental study. Games and Economic Behavior, 66, 506-525.

Tullock, G. (1980). Efficient rent seeking. In James M. Buchanan, Robert D. Tollison, Gordon Tullock, (Eds.), Toward a theory of the rent-seeking society. College Station, TX: Texas A\&M University Press, pp. 97-112.

Van Huyck, J.B., Battalio, R.C., \& Beil, R.O. (1990). Tacit coordination games, strategic uncertainty, and coordination failure. American Economic Review, 80, 234-248.

Van Huyck, J.B., Battalio, R.C., \& Beil, R.O. (1993). Asset markets as an equilibrium selection mechanism: Coordination failure, game form auctions, and tacit communication. Games and Economic Behavior, 5, 485-504.

Zhang, J. (2009). Communication in asymmetric group competition over public goods. Working Paper. 
Figure 1: Nash equilibria when neither group $A$ nor group $B$ can communicate (NC-NC)

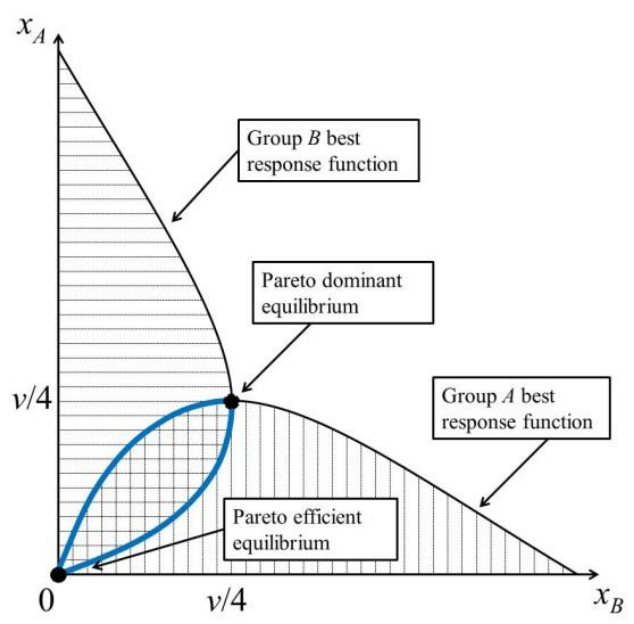

Figure 2: Nash equilibrium when both group $A$ and group $B$ can communicate (C-C)

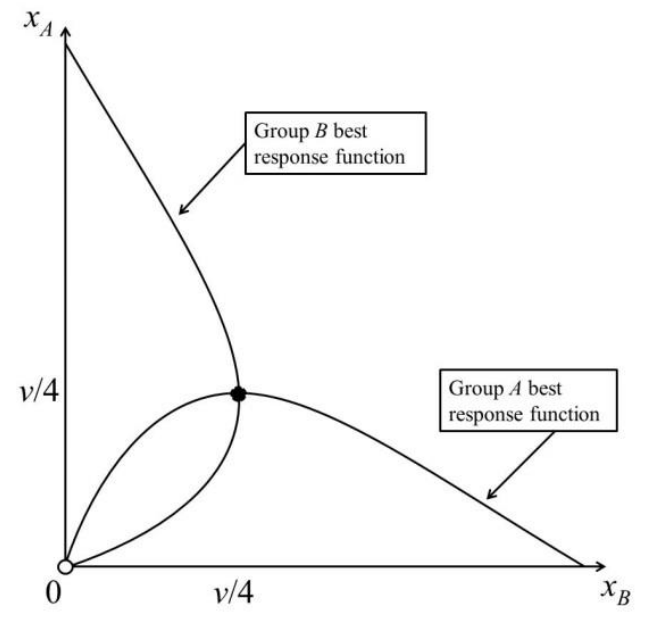

Figure 3: Nash equilibria when only group $A$ can communicate (C-NC)

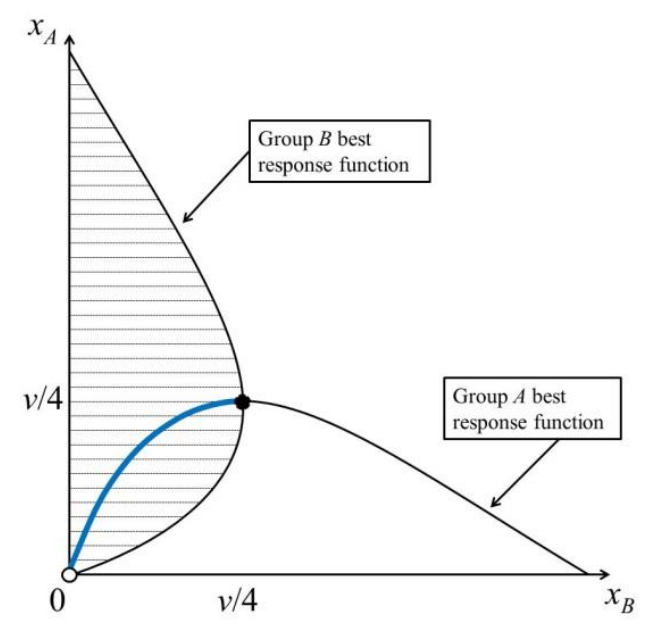


Figure 4: Effective group effort over time by treatment

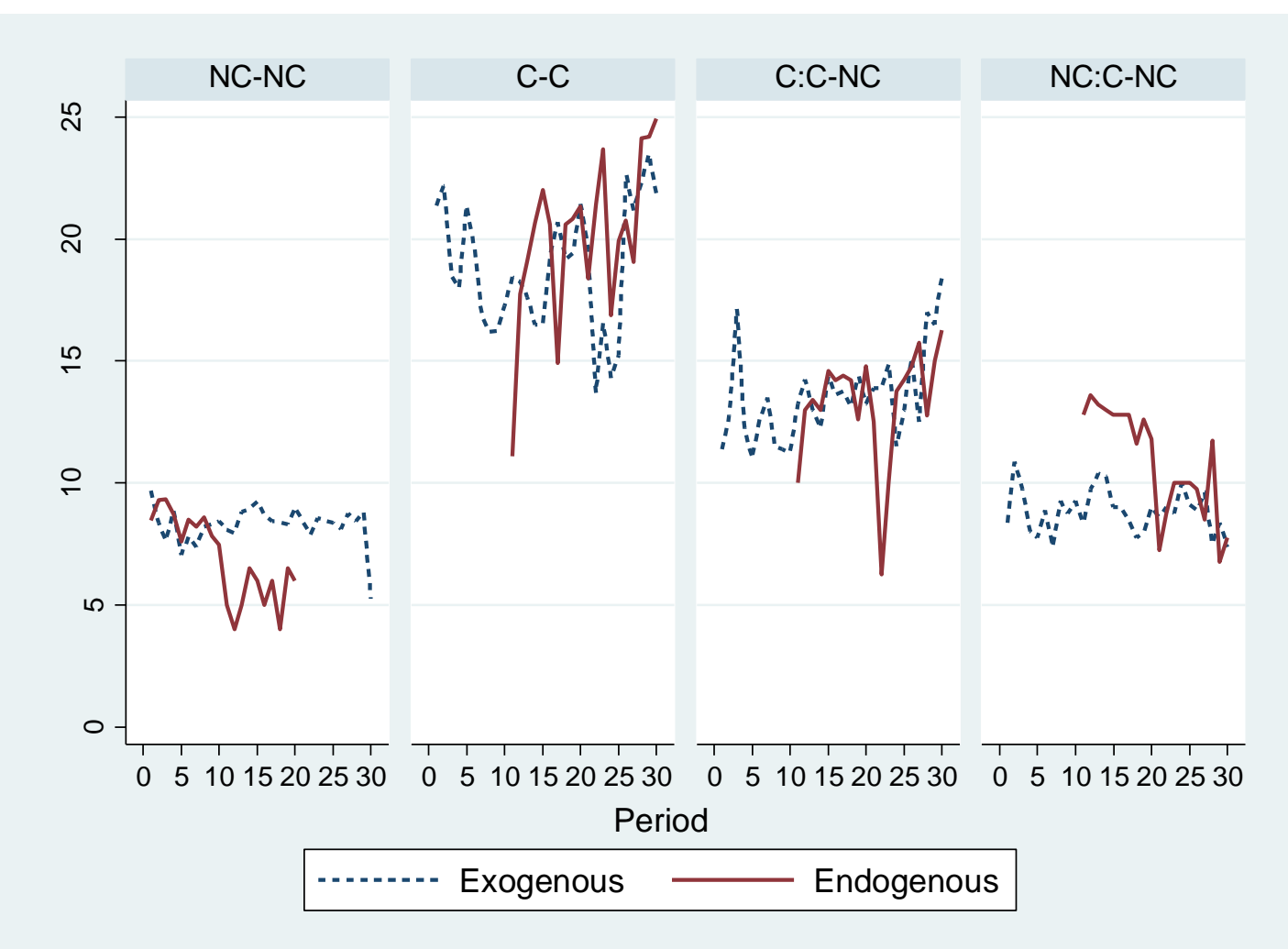


Figure 5: Comparing behavior in the Endogenous treatment to the Exogenous treatment
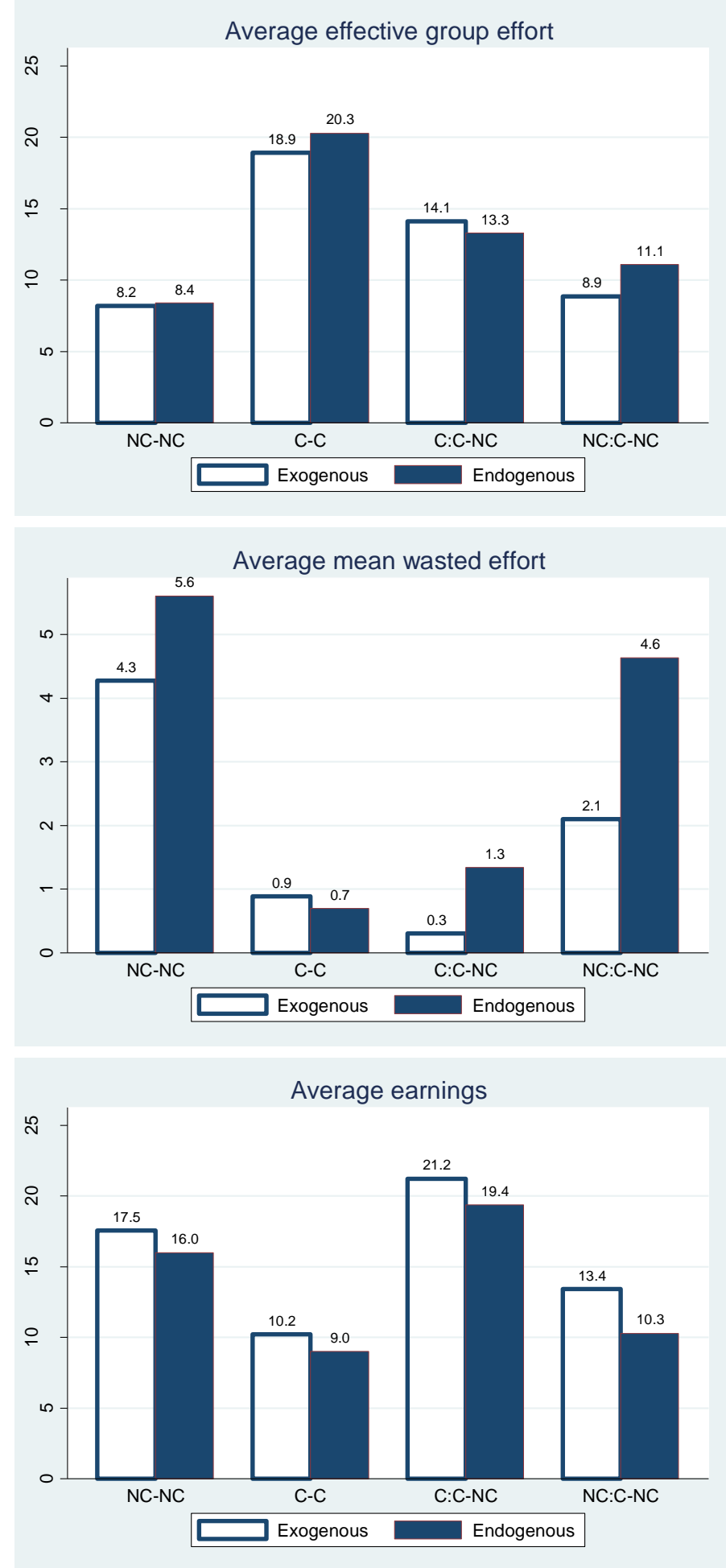


\section{Table 1: Experimental design of treatments}

\begin{tabular}{ll}
\hline \hline Treatment & Independent Groups and Subjects \\
\hline NC-NC & 8 Group pairs and 48 Subjects \\
C-C & 8 Group pairs and 48 Subjects \\
C-NC & 8 Group pairs and 48 Subjects \\
Endogenous & 12 Group pairs and 72 Subjects \\
\hline
\end{tabular}

Table 2: Summary statistics by treatment (all periods)

\begin{tabular}{lcccc}
\hline \hline & \multicolumn{4}{c}{ Average } \\
\cline { 2 - 5 } Treatment & $\begin{array}{c}\text { Group Effective } \\
\text { Effort }\end{array}$ & $\begin{array}{c}\text { Individual } \\
\text { Effort }\end{array}$ & $\begin{array}{c}\text { Wasted } \\
\text { Effort }\end{array}$ & $\begin{array}{c}\text { Expected } \\
\text { Payoff }\end{array}$ \\
\hline Exogenous Communication & & & & \\
\hline NC-NC & 8.29 & 11.18 & 2.89 & 18.82 \\
& $(0.12)$ & $(0.20)$ & $(0.16)$ & $(0.29)$ \\
C-C & 18.86 & 20.13 & 1.27 & 9.87 \\
& $(0.30)$ & $(0.31)$ & $(0.14)$ & $(0.37)$ \\
C-NC & 8.85 & 11.30 & 2.45 & 12.01 \\
(non-communicating group) & $(0.18)$ & $(0.23)$ & $(0.17)$ & $(0.35)$ \\
C-NC & 13.56 & 13.99 & 0.43 & 22.71 \\
(communicating group) & $(0.23)$ & $(0.23)$ & $(0.07)$ & $(0.38)$ \\
\hline Endogenous Communication & & & & \\
\hline en_NC-NC & 8.17 & 13.50 & 5.33 & 16.40 \\
& $(0.19)$ & $(0.39)$ & $(0.35)$ & $(0.60)$ \\
en_C-C & 20.29 & 20.98 & 0.70 & 8.87 \\
& $(0.39)$ & $(0.39)$ & $(0.12)$ & $(0.43)$ \\
en_C-NC & 11.08 & 15.71 & 4.64 & 11.66 \\
(non-communicating group) & $(0.30)$ & $(0.62)$ & $(0.55)$ & $(0.76)$ \\
en_C-NC & 13.29 & 14.63 & 1.34 & 17.99 \\
(communicating group) & $(0.31)$ & $(0.41)$ & $(0.25)$ & $(0.48)$ \\
\hline Standary & & & &
\end{tabular}

Standard errors shown in parentheses.

Table 3: Choice of endogenous communication by periods

\begin{tabular}{lccc}
\hline \hline Group ID & Periods 1-10 & Periods 11-20 & Periods 21-30 \\
\hline & (Exogenous) & \multicolumn{2}{c}{ Endogenous Choice } \\
\hline 5(A,B), 6(A,B), 9(A,B), 10(A,B), 12(A,B) & NC-NC & C-C & C-C \\
1(A,B), 8(A,B), 11(A,B) & NC-NC & C-NC & C-C \\
2(A,B), 7(A,B) & NC-NC & C-NC & C-NC \\
$3(A, B)$ & NC-NC & C-C & C-NC \\
4(A,B) & NC-NC & NC-NC & C-NC \\
\hline
\end{tabular}




\section{Table 4: Categories for coding messages and observed frequency in chat rooms}

\begin{tabular}{|c|c|c|c|c|c|c|c|c|c|}
\hline \multirow[b]{3}{*}{ Category } & \multirow[b]{3}{*}{ Description } & \multicolumn{8}{|c|}{ Relative Frequency of Coding } \\
\hline & & \multicolumn{4}{|c|}{ Exogenous Communication } & \multicolumn{4}{|c|}{ Endogenous Communication } \\
\hline & & $\begin{array}{c}\mathrm{C}-\mathrm{C} \\
(\mathrm{Obs} 472) \\
\end{array}$ & Kappa & $\begin{array}{c}\text { C-NC } \\
(\mathrm{Obs} 238) \\
\end{array}$ & Kappa & $\begin{array}{c}\mathrm{C}-\mathrm{C} \\
(\mathrm{Obs} 280) \\
\end{array}$ & Kappa & $\begin{array}{c}\mathrm{C}-\mathrm{NC} \\
(\mathrm{Obs} 89) \\
\end{array}$ & Kappa \\
\hline$C 1$ & Learning and best response & & & & & & & & \\
\hline Cla & Look back one period & 0.20 & 0.66 & 0.20 & 0.43 & 0.30 & 0.47 & 0.38 & 0.38 \\
\hline$C 1 b$ & $\begin{array}{l}\text { Look back at all or some (multiple) past periods, } \\
\text { not just last period }\end{array}$ & 0.10 & 0.42 & 0.12 & 0.42 & 0.12 & 0.59 & 0.10 & 0.75 \\
\hline$C 1 c$ & $\begin{array}{l}\text { Make choices by reasoning from the other group's } \\
\text { point of view }\end{array}$ & 0.26 & 0.70 & 0.16 & 0.52 & 0.38 & 0.73 & 0.19 & 0.56 \\
\hline$C 2$ & Communication within group & & & & & & & & \\
\hline$C 2 a$ & Agreement reached within group & 0.82 & 0.64 & 0.76 & 0.76 & 0.92 & 0.57 & 0.84 & 0.69 \\
\hline$C 2 b$ & No agreement reached within group & 0.06 & 0.52 & 0.07 & 0.34 & 0.05 & 0.49 & 0.06 & 0.32 \\
\hline$C 2 c$ & Try not to compete/cooperate by lowering effort & 0.23 & 0.67 & 0.16 & 0.59 & 0.19 & 0.80 & 0.13 & 0.85 \\
\hline$C 2 d$ & Try to win/compete by raising effort & 0.33 & 0.55 & 0.17 & 0.85 & 0.38 & 0.73 & 0.31 & 0.74 \\
\hline$C 2 e$ & $\begin{array}{l}\text { Try to match with the opponent group effort from } \\
\text { last period }\end{array}$ & 0.04 & 0.27 & 0.01 & -0.01 & 0.05 & 0.31 & 0.03 & 0.66 \\
\hline$C 2 f$ & Try to win/compete by being unpredictable & 0.03 & 0.21 & 0.03 & -0.03 & 0.04 & 0.14 & 0.01 & -0.01 \\
\hline$C 2 g$ & Stick with the same strategy & 0.37 & 0.82 & 0.40 & 0.82 & 0.30 & 0.79 & 0.32 & 0.80 \\
\hline$C 2 h$ & $\begin{array}{l}\text { Cooperate until the other group defects or until the } \\
\text { last period to defect }\end{array}$ & 0.00 & N/A & 0.03 & 0.41 & 0.01 & -0.01 & 0.01 & -0.01 \\
\hline$C 2 i$ & Luck & 0.10 & 0.51 & 0.08 & 0.60 & 0.09 & 0.65 & 0.11 & 0.59 \\
\hline$C 3$ & Opportunity to communicate & & & & & & & & \\
\hline$C 3 a$ & Positive attitude & 0.00 & N/A & 0.02 & 0.53 & 0.01 & 0.86 & 0.06 & 0.90 \\
\hline$C 3 b$ & Negative attitude & 0.00 & N/A & 0.00 & N/A & 0.01 & 0.66 & 0.01 & 1.00 \\
\hline$C 4$ & Other & & & & & & & & \\
\hline$C 4 a$ & Verbal bullying or punishment & 0.03 & 0.63 & 0.01 & -0.01 & 0.01 & 0.86 & 0.01 & 1.00 \\
\hline$C 4 b$ & Nothing relevant or fits & 0.05 & 0.56 & 0.16 & 0.78 & 0.00 & N/A & 0.03 & 1.00 \\
\hline
\end{tabular}


Table 5: Effects of communication on individual effort choices (last 20 periods)

\begin{tabular}{|c|c|c|c|c|}
\hline \multirow[b]{2}{*}{ Dependent variable, Effort $t_{t}$} & \multicolumn{4}{|c|}{ Treatment and Data Subset } \\
\hline & $\mathrm{C}-\mathrm{C}$ & $\mathrm{C}-\mathrm{NC}$ & en_C-C & en_C-NC \\
\hline Model & (1) & (2) & (3) & (4) \\
\hline $\begin{array}{l}\text { Othergroup-effort } t_{t-1} \\
\text { [effective effort of other in } t-1]\end{array}$ & $\begin{array}{c}-0.08 \\
(0.062)\end{array}$ & $\begin{array}{c}0.21 \\
(0.137)\end{array}$ & $\begin{array}{c}0.16 \\
(0.093)\end{array}$ & $\begin{array}{c}0.63 \\
(0.502)\end{array}$ \\
\hline $\begin{array}{l}\text { Othergroup-effort } t_{-1} \wedge 2 \\
\text { [squared effective effort of other in } t-1]\end{array}$ & $\begin{array}{c}0.00 * \\
(0.002)\end{array}$ & $\begin{array}{l}-0.00 \\
(0.007)\end{array}$ & $\begin{array}{c}-0.00 \\
(0.002)\end{array}$ & $\begin{array}{c}-0.02 \\
(0.018)\end{array}$ \\
\hline $\begin{array}{l}\text { Risk } \\
\text { [number of risky options B] }\end{array}$ & $\begin{array}{c}0.05 \\
(0.136)\end{array}$ & $\begin{array}{c}0.01 \\
(0.078)\end{array}$ & $\begin{array}{c}0.16 \\
(0.119)\end{array}$ & $\begin{array}{l}-0.37 \\
(0.323)\end{array}$ \\
\hline $\begin{array}{l}\text { Group-effort } t-1 \\
\text { [effective group effort in } t-1 \text { ] }\end{array}$ & $\begin{array}{l}0.67 * * \\
(0.051)\end{array}$ & $\begin{array}{l}0.80^{* * *} \\
(0.053)\end{array}$ & $\begin{array}{l}0.61 * * \\
(0.034)\end{array}$ & $\begin{array}{l}0.45^{* *} \\
(0.105)\end{array}$ \\
\hline $\begin{array}{l}\text { 1/period } \\
\text { [inverse of period number } t]\end{array}$ & $\begin{array}{l}-30.94 * \\
(12.407)\end{array}$ & $\begin{array}{c}-14.26 \\
(10.070)\end{array}$ & $\begin{array}{l}-44.19^{*} \\
(19.216)\end{array}$ & $\begin{array}{c}-1.64 \\
(17.200)\end{array}$ \\
\hline Constant & $\begin{array}{l}9.36 * * \\
(1.968)\end{array}$ & $\begin{array}{l}1.82 * * \\
(0.690)\end{array}$ & $\begin{array}{l}6.75^{* *} \\
(2.617)\end{array}$ & $\begin{array}{c}4.97 \\
(3.483)\end{array}$ \\
\hline $\begin{array}{l}\text { Messages } \\
\text { [average \# of interruption per subject in chat] }\end{array}$ & $\begin{array}{l}-0.25 \\
(0.276)\end{array}$ & $\begin{array}{c}0.09 \\
(0.232)\end{array}$ & $\begin{array}{l}1.13^{* *} \\
(0.224)\end{array}$ & $\begin{array}{l}0.87^{* *} \\
(0.155)\end{array}$ \\
\hline $\begin{array}{l}\text { Cla } \\
\text { [look back one period] }\end{array}$ & $\begin{array}{c}0.49 \\
(0.800)\end{array}$ & $\begin{array}{c}0.08 \\
(0.542)\end{array}$ & $\begin{array}{l}-1.76^{*} \\
(0.832)\end{array}$ & $\begin{array}{l}-0.30 \\
(0.225)\end{array}$ \\
\hline $\begin{array}{l}C 1 b \\
{[\text { look back at all or some (multiple) periods }]}\end{array}$ & $\begin{array}{l}-0.61 \\
(0.709)\end{array}$ & $\begin{array}{l}1.17 * * \\
(0.359)\end{array}$ & $\begin{array}{l}-0.95 \\
(0.853)\end{array}$ & $\begin{array}{l}-1.00 \\
(0.613)\end{array}$ \\
\hline $\begin{array}{l}\text { Clc } \\
\text { [make choices reasoning from other's view] }\end{array}$ & $\begin{array}{l}-0.79 \\
(0.614)\end{array}$ & $\begin{array}{l}-2.33^{* *} \\
(0.569)\end{array}$ & $\begin{array}{l}-1.22 * * \\
(0.467)\end{array}$ & $\begin{array}{l}-0.94 \\
(1.061)\end{array}$ \\
\hline $\begin{array}{l}C 2 a \\
\text { [agreement reached within group] }\end{array}$ & $\begin{array}{l}1.75 \\
(1.378)\end{array}$ & $\begin{array}{c}0.57 \\
(1.152)\end{array}$ & $\begin{array}{l}-3.60 \\
(2.197)\end{array}$ & $\begin{array}{c}0.28 \\
(1.319)\end{array}$ \\
\hline $\begin{array}{l}C 2 b \\
\text { [no agreement reached within group] }\end{array}$ & $\begin{array}{l}-3.17 \\
(1.789)\end{array}$ & & $\begin{array}{c}-5.47 \\
(3.019)\end{array}$ & \\
\hline $\begin{array}{l}C 2 c \\
\text { [try not to compete/cooperate by lowering effort] }\end{array}$ & $\begin{array}{c}-10.53 * * \\
(1.226)\end{array}$ & $\begin{array}{l}-4.60 * * \\
(1.128)\end{array}$ & $\begin{array}{c}-11.42 * * \\
(1.264)\end{array}$ & $\begin{array}{l}-1.98 \\
(1.562)\end{array}$ \\
\hline $\begin{array}{l}C 2 d \\
\text { [try to win/compete by raising effort] }\end{array}$ & $\begin{array}{l}5.66^{* *} \\
(0.986)\end{array}$ & $\begin{array}{l}5.13 * * \\
(0.782)\end{array}$ & $\begin{array}{l}10.84 * * \\
(1.098)\end{array}$ & $\begin{array}{c}0.29 \\
(0.976)\end{array}$ \\
\hline $\begin{array}{l}C 2 e \\
\text { [try to match with the opponent group effort] }\end{array}$ & & & & $\begin{array}{c}0.25 \\
(1.300)\end{array}$ \\
\hline $\begin{array}{l}C 2 g \\
\text { [stick with the same strategy] }\end{array}$ & $\begin{array}{c}-2.87 * * \\
(0.617)\end{array}$ & $\begin{array}{c}0.40 \\
(1.095)\end{array}$ & $\begin{array}{c}1.66 \\
(0.929)\end{array}$ & $\begin{array}{c}0.26 \\
(0.922)\end{array}$ \\
\hline $\begin{array}{l}C 2 h \\
\text { [cooperate until the other group defects or the last period] }\end{array}$ & & $\begin{array}{l}-1.66 \\
(0.979)\end{array}$ & & \\
\hline $\begin{array}{l}C 2 i \\
{[\text { luck] }}\end{array}$ & $\begin{array}{c}0.94 \\
(1.065)\end{array}$ & $\begin{array}{l}-1.20^{*} \\
(0.583)\end{array}$ & $\begin{array}{l}-0.75 \\
(0.580)\end{array}$ & $\begin{array}{c}0.41 \\
(0.585)\end{array}$ \\
\hline $\begin{array}{l}\text { C3a } \\
\text { [positive statements about being able to communicate] }\end{array}$ & & $\begin{array}{c}0.32 \\
(0.822)\end{array}$ & $\begin{array}{l}7.40^{* *} \\
(1.276)\end{array}$ & $\begin{array}{l}-1.50 * * \\
(0.538)\end{array}$ \\
\hline $\begin{array}{l}C 3 b \\
\text { [negative statements about being able to communicate] }\end{array}$ & & & $\begin{array}{l}-4.98 * * \\
(0.678)\end{array}$ & $\begin{array}{l}-0.07 \\
(1.318)\end{array}$ \\
\hline $\begin{array}{l}C 4 a \\
\text { [verbal bullying or punishment] }\end{array}$ & $\begin{array}{c}15.27 * * \\
(1.832) \\
\end{array}$ & & $\begin{array}{c}16.46 * * \\
(1.674) \\
\end{array}$ & $\begin{array}{l}5.63 * * \\
(1.151) \\
\end{array}$ \\
\hline Observations & 936 & 474 & 786 & 249 \\
\hline Number of Subjects & 48 & 24 & 54 & 21 \\
\hline
\end{tabular}

* significant at 5\%, ** significant at $1 \%$. Standard errors robust to general heteroscedasticity are shown in parentheses. All models include a random effects error structure, with individual subject effects. 


\section{Appendix (Not for Publication) - Experiment Instructions}

\section{GENERAL INSTRUCTIONS}

This is an experiment in the economics of strategic decision making. Various research agencies have provided funds for this research. The instructions are simple. If you follow them closely and make appropriate decisions, you can earn an appreciable amount of money.

The experiment will proceed in two parts. Each part contains decision problems that require you to make a series of economic choices which determine your total earnings. The currency used in Part 1 of the experiment is U.S. Dollars. The currency used in Part 2 of the experiment is francs. Francs will be converted to U.S. Dollars at a rate of $\mathbf{2 5}$ francs to $\mathbf{1}$ dollar. At the end of today's experiment, you will be paid in private and in cash. $\mathbf{1 2}$ participants are in today's experiment.

It is very important that you remain silent and do not look at other people's work. If you have any questions, or need assistance of any kind, please raise your hand and an experimenter will come to you. If you talk, laugh, exclaim out loud, etc., you will be asked to leave and you will not be paid. We expect and appreciate your cooperation.

At this time we proceed to Part 1 of the experiment.

\section{INSTRUCTIONS FOR PART 1 YOUR DECISION}

In this part of the experiment you will be asked to make a series of choices in decision problems. How much you receive will depend partly on chance and partly on the choices you make. The decision problems are not designed to test you. What we want to know is what choices you would make in them. The only right answer is what you really would choose.

For each line in the table in the next page, please state whether you prefer option A or option B. Notice that there are a total of $\mathbf{1 5}$ lines in the table but just one line will be randomly selected for payment. You ignore which line will be paid when you make your choices. Hence you should pay attention to the choice you make in every line. After you have completed all your choices a token will be randomly drawn out of a bingo cage containing tokens numbered from 1 to 15. The token number determines which line is going to be paid.

Your earnings for the selected line depend on which option you chose: If you chose option A in that line, you will receive $\mathbf{\$ 1}$. If you chose option B in that line, you will receive either $\mathbf{\$ 3}$ or $\mathbf{\$ 0}$. To determine your earnings in the case you chose option B there will be second random draw. A token will be randomly drawn out of the bingo cage now containing twenty tokens numbered from 1 to 20. The token number is then compared with the numbers in the line selected (see the table). If the token number shows up in the left column you earn $\$ 3$. If the token number shows up in the right column you earn $\$ 0$.

\begin{tabular}{|l||l||l|l||l|}
\hline $\begin{array}{l}\text { Deci } \\
\text { ion } \\
\text { no. }\end{array}$ & $\begin{array}{c}\text { Option } \\
\mathbf{A}\end{array}$ & \multicolumn{1}{|c|}{$\begin{array}{c}\text { Option } \\
\mathbf{B}\end{array}$} & $\begin{array}{l}\text { Please } \\
\text { choose } \\
\text { A or B }\end{array}$ \\
\hline 1 & $\mathbf{\$ 1}$ & $\mathbf{\$ 3}$ never & $\mathbf{\$ 0}$ if $1,2,3,4,5,6,7,8,9,10,11,12,13,14,15,16,17,18,19,20$ & \\
\hline 2 & $\mathbf{\$ 1}$ & $\mathbf{\$ 3}$ if 1 comes out of the bingo cage & $\mathbf{\$ 0}$ if $2,3,4,5,6,7,8,9,10,11,12,13,14,15,16,17,18,19,20$ & \\
\hline 3 & $\mathbf{\$ 1}$ & $\mathbf{\$ 3}$ if 1 or 2 & $\mathbf{\$ 0}$ if $3,4,5,6,7,8,9,10,11,12,13,14,15,16,17,18,19,20$ & \\
\hline 4 & $\mathbf{\$ 1}$ & $\mathbf{\$ 3}$ if $1,2,3$ & $\mathbf{\$ 0}$ if $4,5,6,7,8,9,10,11,12,13,14,15,16,17,18,19,20$ & \\
\hline 5 & $\mathbf{\$ 1}$ & $\mathbf{\$ 3}$ if $1,2,3,4$, & $\mathbf{\$ 0}$ if $5,6,7,8,9,10,11,12,13,14,15,16,17,18,19,20$ & \\
\hline 6 & $\mathbf{\$ 1}$ & $\mathbf{\$ 3}$ if $1,2,3,4,5$ & $\mathbf{\$ 0}$ if $6,7,8,9,10,11,12,13,14,15,16,17,18,19,20$ & \\
\hline 7 & $\mathbf{\$ 1}$ & $\mathbf{\$ 3}$ if $1,2,3,4,5,6$ & $\mathbf{\$ 0}$ if $7,8,9,10,11,12,13,14,15,16,17,18,19,20$ & \\
\hline 8 & $\mathbf{\$ 1}$ & $\mathbf{\$ 3}$ if $1,2,3,4,5,6,7$ & $\mathbf{\$ 0}$ if $8,9,10,11,12,13,14,15,16,17,18,19,20$ & \\
\hline 9 & $\mathbf{\$ 1}$ & $\mathbf{\$ 3}$ if $1,2,3,4,5,6,7,8$ & $\mathbf{\$ 0}$ if $9,10,11,12,13,14,15,16,17,18,19,20$ & \\
\hline 10 & $\mathbf{\$ 1}$ & $\mathbf{\$ 3}$ if $1,2,3,4,5,6,7,8,9$ & $\mathbf{\$ 0}$ if $10,11,12,13,14,15,16,17,18,19,20$ & \\
\hline 11 & $\mathbf{\$ 1}$ & $\mathbf{\$ 3}$ if $1,2,3,4,5,6,7,8,9,10$ & $\mathbf{\$ 0}$ if $11,12,13,14,15,16,17,18,19,20$ & \\
\hline 12 & $\mathbf{\$ 1}$ & $\mathbf{\$ 3}$ if $1,2,3,4,5,6,7,8,9,10,11$ & $\mathbf{\$ 0}$ if $12,13,14,15,16,17,18,19,20$ & \\
\hline 13 & $\mathbf{\$ 1}$ & $\mathbf{\$ 3}$ if $1,2,3,4,5,6,7,8,9,10,11,12$ & $\mathbf{\$ 0}$ if $13,14,15,16,17,18,19,20$ & \\
\hline 14 & $\mathbf{\$ 1}$ & $\mathbf{\$ 3}$ if $1,2,3,4,5,6,7,8,9,10,11,12,13$ & $\mathbf{\$ 0}$ if $14,15,16,17,18,19,20$ & \\
\hline 15 & $\mathbf{\$ 1}$ & $\mathbf{\$ 3}$ if $1,2,3,4,5,6,7,8,9,10,11,12,13,14$ & $\mathbf{\$ 0}$ if $15,16,17,18,19,20$ & \\
\hline
\end{tabular}




\section{INSTRUCTIONS FOR PART 2 \\ YOUR DECISION}

The second part of the experiment consists of $\mathbf{3 0}$ decision-making periods. At the beginning of the first period, you will be randomly and anonymously placed into a group of $\mathbf{3}$ people: group A or group B. You will remain in the same group for all 30 periods of the experiment. At the beginning of the first period, your group will be paired with another group. This pairing remains the same for all 30 periods of the experiment. Either group A or group B will receive a reward. The reward is $\mathbf{6 0}$ francs to each group member.

Each period you will be given an endowment of $\mathbf{6 0}$ francs and asked to decide how much to allocate to the group account or the individual account. You may allocate any integer number of francs between $\mathbf{0}$ and $\mathbf{6 0}$. An example of your decision screen is shown below.

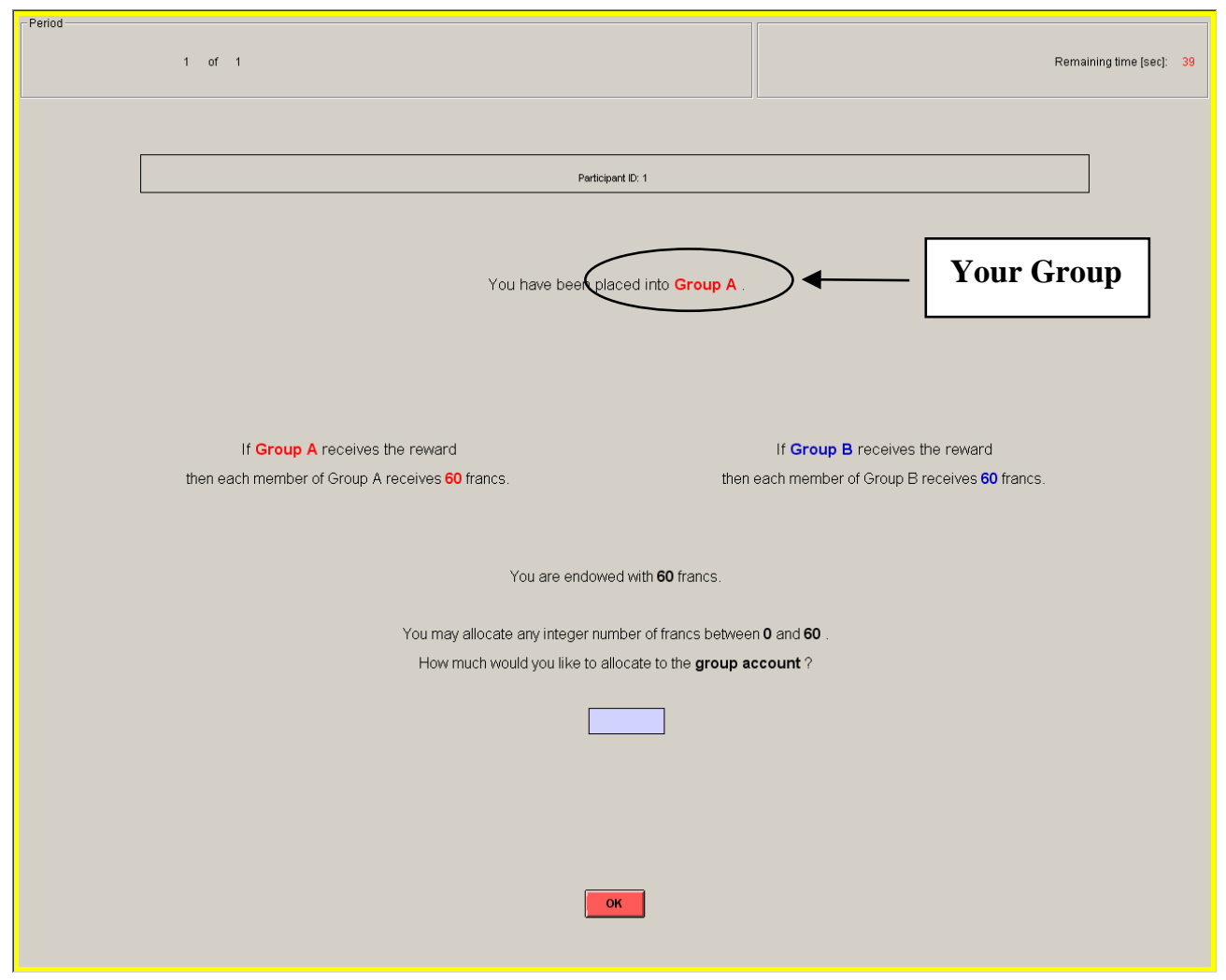

\section{COMMUNICATION}

In some periods before they are asked to make the allocation decision, participants may have an opportunity to communicate with the other two participants in their own group. This communication will consist of messages exchanged in a "chat area" shown on their computer screen. Any messages sent in this chat will only be viewed by you and the other two members in your group. The chat time will be active for 60 seconds each period that this communication opportunity is available. In periods that the communication opportunity is not available, there will be a 60 second break each period before the allocation decision.

Although we will record the messages you send to each other, your chat id remains anonymous. The first person to send a message in a period will always be referred to as "member 1", the second as "member 2" and so on. In sending messages, you should follow two basic rules: (1) be civil to one another and do not use profanities, and (2) do not identify yourself in any manner. The communication channel is intended to discuss your allocation choices and should be used that way.

After the chat period is over, all group members then make their actual decisions simultaneously; you do not learn the actual allocation decisions of your group members until after you make your decision.

In decision-making periods 1-10 there will be no opportunity for communication. Before period 11 you and the other two participants in your group will vote to determine whether to communicate each period before making an allocation in periods 11-20. Only if all three participants unanimously vote to communicate will the chat room be created for communication. Before period 21 another vote will determine whether you and your group communicate 
each period before making an allocation in periods 21-30. Again, communication will occur only if all three participants unanimously vote to communicate.

Both groups will vote before periods 11 and 21, so in some cases both groups A and B might communicate, in other cases neither group A nor B communicate, and in other cases only one of the two groups will communicate. Your decision screen where you make your allocation will always indicate which (if any) of the two groups communicated that period.

\section{YOUR EARNINGS}

After all participants have made their decisions, your earnings for the period are calculated. These earnings will be converted to cash and paid at the end of the experiment if the current period is one of the five periods that is randomly chosen for payment.

1) Your period earnings are the sum of the earnings from your individual account and the earnings from your group account.

2) For each franc in your individual account, you will earn $\mathbf{1}$ franc in return. So, if you keep all 60 francs that you are endowed with to your individual account you will earn 60 francs. But you can also earn some francs from your group account.

3) By contributing to the group account you may increase the chance of receiving the reward for your group. In determining which group receives the reward, the computer will consider only the lowest contribution in group A's account and the lowest contribution in group B's account. If the lowest contribution in group A's account exceeds the lowest contribution in group B's account, group A has higher chance of receiving the reward and vise-versa. In particular, your group's chance of receiving the reward is

(Your Group's Minimum Bid)/(Minimum Bid in group A + Minimum Bid in group B)

If both group's minimum bids are 0 , the reward is randomly assigned to one of the two groups.

4) If your group receives the reward then in addition to the earnings from your individual account you receive the reward of $\mathbf{6 0}$ francs from your group account. A group can never guarantee itself the reward. However, by increasing your contribution, you can increase your group's chance of receiving the reward.

5) The computer will assign the reward either to your group or to the other group, via a random draw. So, in each period, only one of the two groups can obtain the reward.

\section{Example: Random Draw and Earnings}

This is a hypothetical example used to illustrate how the computer is making a random draw. Let's say the members of groups A and B allocate their francs in the following way.

Table 1 - Allocation of francs by all members in group A and B

\begin{tabular}{|l|c|c|c|}
\hline Group A & $\begin{array}{c}\text { If Group } \\
\text { A } \\
\text { receives } \\
\text { reward }\end{array}$ & $\begin{array}{c}\text { Allocation } \\
\text { to } \\
\text { individual } \\
\text { account }\end{array}$ & $\begin{array}{c}\text { Allocation } \\
\text { to group } \\
\text { account }\end{array}$ \\
\hline Member 1 & 60 & 40 & 20 \\
Member 2 & 60 & 45 & 15 \\
Member 3 & 60 & 50 & $\mathbf{1 0}$ \\
\hline
\end{tabular}

\begin{tabular}{|c|c|c|c|}
\hline Group B & $\begin{array}{c}\text { If Group } \\
\text { B } \\
\text { receives } \\
\text { reward }\end{array}$ & $\begin{array}{c}\text { Allocation } \\
\text { to } \\
\text { individual } \\
\text { account }\end{array}$ & $\begin{array}{c}\text { Allocation } \\
\text { to group } \\
\text { account }\end{array}$ \\
\hline Member 1 & 60 & 59 & $\mathbf{1}$ \\
Member 2 & 60 & 50 & 10 \\
Member 3 & 60 & 55 & 5 \\
\hline
\end{tabular}

In group A, member 1 contributes 20 francs, member 2 contributes 15 francs, and member 3 contributes 10 francs to group A's account. In group B, member 1 contributes 1 franc, member 2 contributes 10 francs, and member 3 contributes 5 francs to group B' account.

Then the computer chooses the lowest contribution in group A's account and the lowest contribution in group B's account. The two highest contributions in group A and the two highest contributions in group B will not be considered by the computer. In this example, member 3 has the lowest contribution of $\mathbf{1 0}$ francs in group A and member 1 has the lowest contribution of $\mathbf{1}$ franc in group B. For each franc of member 3 in group A the computer puts 1 red token into a bingo cage and for each franc of member 1 in group B the computer puts 1 blue token. Thus, the computer places 10 red tokens and 1 blue token into the bingo cage (11 tokens total). Then the computer randomly draws one token out of the bingo cage. If the drawn token is red group A receives the reward, if the token is blue group B receives the reward. You can see that since group A has more tokens it has a higher chance of receiving the reward (10 out of $\mathbf{1 1}$ times group A will receive the reward). Group B has a lower chance of receiving the reward (1 out of 11 times group B will receive the reward). 
Let's say the computer made a random draw and group A receives the reward. Thus, all the members of group A receive the reward of 60 francs from the group account plus they also receive earnings from the individual account. All members of group B receive earnings only from the individual account, since group B does not receive the reward. The calculation of the total earnings is shown in Table 2 below.

Table 2 - Calculation of earning for all members in group A and B

\begin{tabular}{|c|c|c|c|c|c|c|c|}
\hline Group A & $\begin{array}{l}\text { Earnings } \\
\text { from } \\
\text { group } \\
\text { account }\end{array}$ & $\begin{array}{l}\text { Earnings } \\
\text { from } \\
\text { individual } \\
\text { account }\end{array}$ & $\begin{array}{c}\text { Total } \\
\text { earnings }\end{array}$ & Group B & $\begin{array}{l}\text { Earnings } \\
\text { from } \\
\text { group } \\
\text { account }\end{array}$ & $\begin{array}{l}\text { Earnings } \\
\text { from } \\
\text { individual } \\
\text { account }\end{array}$ & $\begin{array}{c}\text { Total } \\
\text { earnings }\end{array}$ \\
\hline Member 1 & 60 & 40 & $60+40=100$ & Member 1 & $\mathbf{0}$ & 59 & 59 \\
\hline Member 2 & 60 & 45 & $60+45=105$ & Member 2 & 0 & 50 & 50 \\
\hline Member 3 & 60 & 50 & $60+50=110$ & Member 3 & 0 & 55 & 55 \\
\hline
\end{tabular}

At the end of each period, the total number of francs in the two groups' accounts, group which receives the reward, earnings from individual and group accounts, and total earnings for the period are reported on the outcome screen as shown on the next page. Please record your results for the period on your record sheet under the appropriate heading.

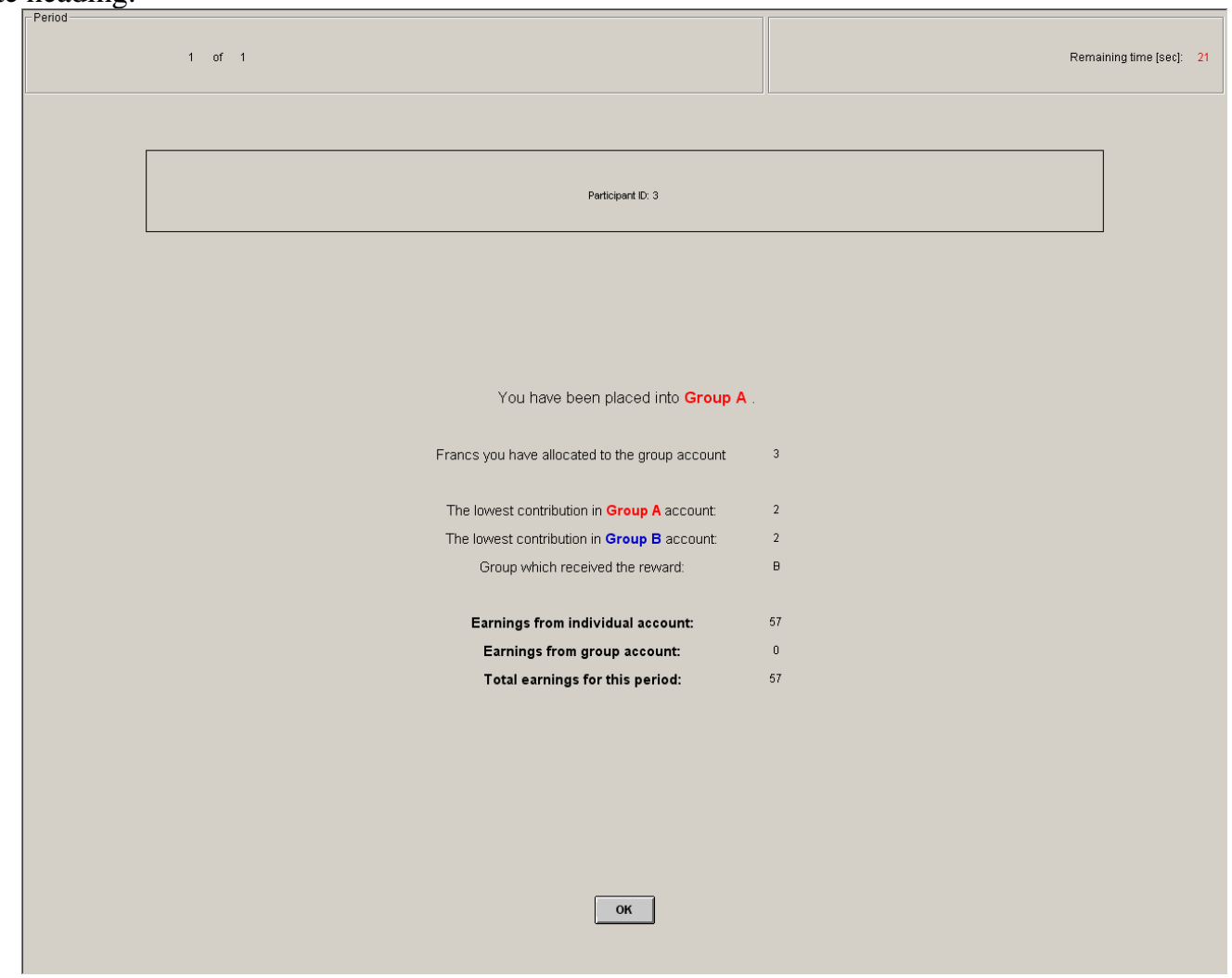

\section{Outcome Screen}

\section{IMPORTANT NOTES}

You will not be told which of the participants in this room are assigned to which group. At the beginning of the first period, you will be randomly and anonymously placed into a group of 3 people: group A or group B. You will remain in the same group for all 30 periods of the experiment. At the beginning of the first period, your group will be paired with another group. This pairing remains the same for all 30 periods of the experiment. Either group A or group B will receive a reward. The reward is $\mathbf{6 0}$ francs to each group member. A group can never guarantee itself the reward. However, by increasing your contribution, you can increase your group's chance of receiving the reward.

At the end of the experiment we will randomly choose $\mathbf{5}$ of the $\mathbf{3 0}$ periods for actual payment in Part $\mathbf{2}$ using a bingo cage. You will sum the total earnings for these 5 periods and convert them to a U.S. dollar payment. 